\title{
Understanding cardiovascular injury after treatment for cancer: an overview of current uses and future directions of cardiovascular magnetic resonance
}

\author{
Sujethra Vasu ${ }^{1}$ and W Gregory Hundley ${ }^{1,2^{*}}$
}

\begin{abstract}
While cancer-free survival has improved over the past 20 years for many individuals with prostate, renal, breast, and hematologic malignancies, the increasingly recognized prevalence of cardiovascular (CV) events in cancer survivors has been an unintended consequence of many of the therapies that have improved these survival rates. The increase in CV events threatens to offset the improvement in cancer related survival. As a result, there is an emerging need to develop methods to identify those individuals treated for cancer at increased risk of cardiovascular events. With its inherent ability to characterize myocardial tissue and identify both cardiac and vascular dysfunction, cardiovascular magnetic resonance (CMR) has the potential to identify both subclinical and early clinical CV injury before the development of an overt catastrophic event such as a myocardial infarction, stroke, or premature cardiac death. Early identification provides an opportunity for the implementation of primary prevention strategies to prevent such events, thereby improving overall cancer survivorship and quality of life. This article reviews the etiology of CV events associated with cancer therapy and the unique potential of CMR to provide early diagnosis of subclinical CV injury related to the administration of these therapies.
\end{abstract}

Keywords: Cardiotoxicity, Chemotherapy, Cancer, Cardiovascular magnetic resonance

\section{Review}

Over the past 20 years, cancer free survival has improved for many individuals with prostate, renal, breast, and hematologic malignancies. Unfortunately, an unintended consequence of many of the therapies that have contributed to this improvement in cancer-free survival has been the increasingly recognized evolution of cardiovascular (CV) events [1-12]. Several recently published research studies provide insight into possible etiologies of these events. Result from studies involving the Centers for Medicare-Medicaid Services (CMS) and Health Maintenance Organization (HMO) databases within the United States indicate an increased prevalence of billing codes for heart failure, myocardial infarction (MI), and

\footnotetext{
*Correspondence: ghundley@wakehealth.edu

'Department of Internal Medicine (Section on Cardiology), Wake Forest School of Medicine, Winston-Salem, North Carolina, USA

2DepartmentRadiology, Wake Forest School of Medicine, Winston-Salem, North Carolina, USA
}

cardiac arrhythmias in patients treated for cancer [1-12]. Also in these studies, there is an increased frequency of codes related to the administration of chemotherapy for cancer that precedes the onset of codes for $\mathrm{CV}$ disease and events. The fact that chemotherapy codes precede $\mathrm{CV}$ event codes in cancer patients implies a temporal relationship between the administration of cancer treatment and the subsequent occurrence of $\mathrm{CV}$ events.

Importantly, the number of cancer survivors who experience subsequent $\mathrm{CV}$ events is large. In the US alone, there are now over 13 million cancer survivors, and for breast cancer alone, it is estimated that over $\$ 800$ million will be spent annually providing $\mathrm{CV}$ care for these women [2-4]. As a result, there is an emerging need to develop accurate, cost-effective methods to identify those individuals treated for cancer at increased risk of CV events.

Cardiovascular magnetic resonance (CMR) with its inherent ability to characterize myocardial tissue and

\section{Biomed Central}


identify both cardiac and vascular dysfunction has the potential to identify both subclinical and early clinical $\mathrm{CV}$ injury before the development of an overt catastrophic event such as a MI, stroke or premature cardiac death. Early identification of subclinical CV injury provides an opportunity for the implementation of primary prevention strategies to prevent these untoward CV events. By reducing CV related events in those treated for cancer, the opportunity exists to improve overall cancer survivorship.

In this article, we review the data indicating an increased incidence of $\mathrm{CV}$ events in cancer survivors, the underlying mechanisms of these events, and the potential of CMR to provide early diagnosis of subclinical $\mathrm{CV}$ injury related to the administration of therapy for cancer, and therefore to guide therapeutic interventions to reduce the overall CV related mortality and morbidity associated with therapy for cancer.

\section{Cardiovascular injury and disease after cancer treatment}

The 5-year survival rate for patients with breast cancer or hematologic malignancies has increased from an average of $53 \%$ in 2007, to upwards of $85 \%$ in 2012 [13,14]. While encouraging, this positive trend in improved cancer-related mortality is tempered by an emerging increase in CV disease, morbidity, and mortality [8]. The reasons for this increase in $\mathrm{CV}$ related events are uncertain; however, the results from several studies suggest that this emergence may be related to the therapies utilized to treat the cancer. Several therapeutic interventions including the administration of chemotherapy [15], immunotherapy [16], hormone deprivation [17] and radiation related therapy $[18,19]$ have been associated with CV related increases in morbidity or mortality. The injuries and abnormalities associated with cancer treatment can be highly variable and depend on the type of cancer treatment received. In Table 1 , a review of the agents previously associated with CV injury is provided. Below, we briefly discuss three categories of agents associated with $\mathrm{CV}$ events.

\section{Myocellular injury due to anthracycline chemotherapy}

In children or adults treated for a hematologic malignancy or women treated for breast cancer, the administration of anthracyclines has been associated with left ventricular (LV) dysfunction and heart failure $[9,20]$. In the Childhood Cancer Survivor Study (CCSS) cohort, which includes children and young adults $<21$ years of age who received chemotherapy beginning in 1994, childhood cancer survivors experienced a relative risk (RR) of 15.1 (95\% confidence interval [CI] 4.8-47.9) of developing congestive heart failure (CHF) when compared to their siblings without cancer or receipt of chemotherapy [20]. In a separate study of 31,748 women diagnosed with breast cancer, anthracycline chemotherapy was associated with the development of cardiomyopathy (hazard ratio [HR] 2.48, 95\% CI 2.1 -2.93) and CHF (HR 1.38, 95\% CI 1.25-1.52) [21].

In addition to CHF, patients exposed to anthracyclines experience other $\mathrm{CV}$ events including $\mathrm{MI}$ and stroke. In the CCSS cohort, children treated with anthracyclines developed coronary artery disease (CAD; RR 10.4, 95\% CI 4.1-25.9) and cerebrovascular accidents (RR 9.3, 95\% CI 4.1-21.1) more frequently than their siblings without cancer [22-26]. Similarly, in women over the age of 65 years treated with adjuvant anthracycline chemotherapy for Stage I or II breast cancer, MI, stroke, and other $\mathrm{CV}$ events were the primary cause of death in those surviving 5 years beyond initiation of their treatment [8].

In adults, the combination of anthracyclines and radiation therapy further increases $\mathrm{CV}$ events, particularly MI. In the British National Lymphoma Investigation database, a higher incidence of MI was noted in survivors of Hodgkin's disease who received radiation therapy and anthracycline-based chemotherapy [27]. The RR of death due to MI after radiation therapy ranged from 1.6 to 9.5 depending on radiation type and the associated chemotherapy regimen utilized in the treatment plan [27]. Furthermore, the RR of death due to MI was 4.1 in the first year after treatment and remained elevated at 2.5 for more than 25 years after treatment.

Similar late risks of cardiac death were noted in 1,080 patients with Hodgkin's lymphoma aged $\leq 50$ years. In these patients, radiation and chemotherapy were associated with cardiac mortality (RR 3.2 [1.9-5.2]) that remained elevated (RR 4.5 [1.2-11.6]) 20 years after treatment [28]. Overall, as described by Yeh et al., the cumulative dose of anthracycline, the concomitant administration of other cardio-toxic agents, prior radiation therapy, female gender, increasing age, or the presence of diabetes or hypertension are risk factors for developing cardiovascular injury upon receipt of anthracycline based chemotherapy with or without radiation therapy [29-33].

\section{Tyrosine kinase inhibitors - trastuzumab}

Tyrosine kinases modulate cellular growth, differentiation and metabolism [34]. Inhibitors of tyrosine kinases have been associated with down regulation of many cancer cell related functions [35]. In general, these agents are of two broad types: monoclonal antibodies, such as trastuzumab and bevacizumab, and small molecule inhibitors, such as lapatinib, imatinib, sorafenib, and sunitinib. Over the past 5 to 10 years, it has been recognized that many of these agents are also associated with several adverse $\mathrm{CV}$ related abnormalities including microvascular injury, hypertension, and LV dysfunction $[35,36]$. The administration of the tyrosine kinase inhibitor trastuzumab to women with HER2-positive breast 
Table 1 Cancer therapeutic agents, risk factors, mechanisms, and manifestations of cardiotoxicity

\begin{tabular}{|c|c|c|c|c|}
\hline $\begin{array}{l}\text { Therapeutic } \\
\text { agent }\end{array}$ & Therapeutic indications & Risk factors & Mechanisms & $\begin{array}{l}\text { Manifestations of } \\
\text { cardiotoxicity }\end{array}$ \\
\hline \multicolumn{5}{|c|}{ Anthracyclines } \\
\hline Doxorubicin & Breast cancer & Concurrent chemotherapy & Cellular apoptosis induction & Early \\
\hline Daunorubicin & Gastric & Dosing schedules & ETC. uncoupling & CHF/LV dysfunction \\
\hline Epirubicin & Leukemias & Elderly & Iron complexation & Myocardial ischemia/infarction \\
\hline \multirow[t]{6}{*}{ Idarubicin } & Lung cancer & Women & $\begin{array}{l}\text { Lipid peroxidation of } \\
\text { myocyte }\end{array}$ & Pericarditis/myocarditis \\
\hline & Lymphomas & Prior radiation & membranes & QT prolongation \\
\hline & Ovarian & IV administration & Nuclear DNA damage & ST-T wave abnormalities \\
\hline & Sarcomas & Underlying CV disease & ROS formation & Late \\
\hline & & & & Cardiomyopathy \\
\hline & & & & CHF/LV dysfunction \\
\hline \multicolumn{5}{|c|}{ Anthraquinolones } \\
\hline \multirow[t]{3}{*}{ Mitoxantrone } & $\mathrm{AML}$ & Unknown & ROS formation & Arrhythmias \\
\hline & & & & $\mathrm{CHF}$ \\
\hline & Breast cancer & & & Myocardial ischemia/infarction \\
\hline
\end{tabular}

$\mathrm{NHL}$

Antimetabolites

5-Fluorouracil

Breast cancer

Underlying CV disease

Endothelial cell damage

Arrhythmias

Colorectal cancer

Vasospasm

$\mathrm{CHF}$

Pancreatic cancer

Myocardial ischemia/infarction

\section{Antimicrotubules}

Paclitaxel Breast cancer Unknown

Hypersensitivity reaction

Bradyarrhythmias

$\mathrm{CHF}$

Kaposi's sarcoma

Lung cancer

Ovarian cancer

Vinca alkaloids Leukemias

Unknown

Vinblastine Lymphomas

Vincristine Nephroblastoma

\section{Alkylating agents}

Busulfan

$\mathrm{CML}$

Unknown

Unknown

Hypotension

Myocardial ischemia/infarction

Possible vasospasm

Autonomic neuropathy

Hypotension

Myocardial ischemia/infarction

Raynaud's phenomenon

Arrhythmias

Pericardial effusion

HTN

Pulmonary fibrosis

$\begin{array}{lll}\text { Cisplatin } & \text { Germ cell tumors } & \text { Elderly } \\ \text { Lung cancer } & \text { Prior mediastinal irradiation } \\ \text { Lymphomas } & \text { Use for metastatic testicular } \\ \text { Ovarian cancer } & \text { cancer } \\ \text { Sarcomas } & \text { Use with cyclophosphamide }\end{array}$

Coronary artery fibrosis

Early

Hypokalemia

$\mathrm{CHF}$

Hypomagnesaemia

Myocardial ischemia/infarction

Late

Arrhythmias

HTN

LVH

Myocardial ischemia/infarction 
Table 1 Cancer therapeutic agents, risk factors, mechanisms, and manifestations of cardiotoxicity (Continued)

\begin{tabular}{|c|c|c|c|c|}
\hline & & CHF/LV dysfunction & & \\
\hline & & Lymphomas & \multirow[t]{2}{*}{ Prior mediastinal irradiation } & \\
\hline & & $\begin{array}{l}\text { Hemorrhagic myocardial } \\
\text { necrosis }\end{array}$ & & \\
\hline \multirow{2}{*}{$\begin{array}{l}\text { Various solid } \\
\text { tumors }\end{array}$} & \multirow[t]{2}{*}{ Prior anthracyclines } & Hemorrhagic pericarditis & & \\
\hline & & LVH & & \\
\hline \multirow[t]{2}{*}{ Ifosfamide } & Lymphomas & High dose regimens & \multirow{2}{*}{$\begin{array}{l}\text { Myocardial fiber } \\
\text { fragmentation }\end{array}$} & Arrhythmias \\
\hline & Various solid tumors & Use for lymphomas & & $\mathrm{CHF}$ \\
\hline \multicolumn{5}{|c|}{ Biological agents } \\
\hline \multirow[t]{5}{*}{ Interferon-a } & Leukemias & & Unknown & Early \\
\hline & Lymphomas & & & Arrhythmias \\
\hline & Melanoma & & & Hypertension \\
\hline & Various solid tumors & & & Late \\
\hline & & & & Cardiomyopathy \\
\hline \multirow[t]{7}{*}{ Interleukin-2 } & Melanoma & & Unknown & Early \\
\hline & $\mathrm{RCC}$ & & & $\begin{array}{l}\text { Hypotension (capillary leak } \\
\text { syndrome) }\end{array}$ \\
\hline & & & & Myocarditis \\
\hline & & & & Thrombotic events \\
\hline & & & & Ventricular arrhythmias \\
\hline & & & & Late \\
\hline & & & & Dilated Cardiomyopathy \\
\hline \multicolumn{5}{|c|}{ Hormone-modifying therapy } \\
\hline \multirow{5}{*}{$\begin{array}{l}\text { Androgen- } \\
\text { deprivation } \\
\text { therapy }\end{array}$} & Prostate cancer & Men over 65 & Development of metabolic & CAD \\
\hline & & Underlying CV disease & syndrome & CHF/LV dysfunction \\
\hline & & & Dyslipidemia & Myocardial ischemia/infarction \\
\hline & & & Insulin resistance & QT prolongation \\
\hline & & & Obesity & SCD \\
\hline \multirow{3}{*}{$\begin{array}{l}\text { Aromatase } \\
\text { Inhibitors }\end{array}$} & Breast cancers & Unknown & Dyslipidemia & CAD \\
\hline & Estrogen receptor $(+)$ & & & CHF/LV dysfunction \\
\hline & & & & Myocardial ischemia/infarction \\
\hline \multicolumn{5}{|c|}{ Miscellaneous } \\
\hline \multirow{5}{*}{$\begin{array}{l}\text { All-trans } \\
\text { retinoic acid } \\
\text { (Tretinoin) }\end{array}$} & APL & Unknown & Unknown & Arrhythmias \\
\hline & & & & $\mathrm{CHF}$ \\
\hline & & & & Hypotension \\
\hline & & & & Myocardial ischemia/infarction \\
\hline & & & & Pericardial effusions \\
\hline \multirow[t]{2}{*}{$\begin{array}{l}\text { Arsenic } \\
\text { trioxide }\end{array}$} & $\mathrm{AML}$ & Unknown & Hypomagnesaemia & $\begin{array}{l}\text { Arrhythmias with QT } \\
\text { prolongation }\end{array}$ \\
\hline & & & & Pericardial effusion \\
\hline \multirow[t]{3}{*}{ Pentostatin } & Hairy cell leukemia & Use with cyclophosphamide & Unknown & $\begin{array}{l}\text { Arrhythmias including A-V } \\
\text { block }\end{array}$ \\
\hline & & & & CHF \\
\hline & & & & Myocardial ischemia/infarction \\
\hline \multicolumn{5}{|c|}{ Radiation therapy } \\
\hline & Various malignancies & Prior high doses of radiation & $\begin{array}{l}\text { Fibrosis caused by } \\
\text { inflammatory }\end{array}$ & Early \\
\hline
\end{tabular}




\section{Table 1 Cancer therapeutic agents, risk factors, mechanisms, and manifestations of cardiotoxicity (Continued)}

\begin{tabular}{|c|c|c|c|c|}
\hline & & Underlying CV disease & changes & Pericarditis/Pericardial effusion \\
\hline & & Use with anthracyclines & ROS formation & Late \\
\hline & & & & CAD \\
\hline & & & & $\mathrm{CHF}$ \\
\hline & & & & Conduction abnormalities \\
\hline & & & & Constrictive pericarditis \\
\hline & & & & Restroctive cardiomyopathy \\
\hline & & & & Valvular defects \\
\hline \multicolumn{5}{|c|}{ Tyrosine-kinase inhibitors } \\
\hline \multirow[t]{3}{*}{ Bevacizumab } & Colorectal cancer & Use with anthracyclines & $\begin{array}{l}\text { Monoclonal antibody against } \\
\text { VEGF }\end{array}$ & $\begin{array}{l}\text { Arterial and venous } \\
\text { thromboembolism }\end{array}$ \\
\hline & HER-2 (-) breast cancer & & $\begin{array}{l}\text { Possible decrease in nitric } \\
\text { oxide and }\end{array}$ & $\mathrm{CHF}$ \\
\hline & Lung cancer & & prostaglandin production & HTN \\
\hline \multirow[t]{2}{*}{ Imatinib } & GIST & Use with anthracyclines & \multirow{2}{*}{$\begin{array}{l}\text { Unclear, but may induce } \\
\text { apoptosis in cardiomyocytes }\end{array}$} & CHF/LV dysfunction \\
\hline & Leukemias & & & Pericardial effusion \\
\hline \multirow[t]{2}{*}{ Lapatinib } & \multirow[t]{2}{*}{ HER-2 (+) breast cancer } & \multirow[t]{2}{*}{ Use with anthracyclines } & \multirow[t]{2}{*}{ Inhibits HER-2 and EGFR } & LV dysfunction \\
\hline & & & & QT prolongation \\
\hline \multirow[t]{5}{*}{ Sorafenib } & $\mathrm{HCC}$ & \multirow[t]{5}{*}{ Use with anthracyclines } & \multirow{5}{*}{$\begin{array}{l}\text { Unclear, but may induce } \\
\text { apoptosis in cardiomyocytes, } \\
\text { or inhibit VEGF and RAF-1 }\end{array}$} & CHF/LV dysfunction \\
\hline & $\mathrm{RCC}$ & & & HTN \\
\hline & & & & Myocardial ischemia/infarction \\
\hline & & & & Thromboembolism \\
\hline & & & & CHF/LV dysfunction \\
\hline \multirow[t]{2}{*}{ Sunitinib } & GIST & \multirow[t]{2}{*}{ Use with anthracyclines } & \multirow{2}{*}{$\begin{array}{l}\text { Unclear, but may induce } \\
\text { apoptosis in cardiomyocytes } \\
\text { and inhibit VEGF }\end{array}$} & HTN \\
\hline & RCC & & & Thrombotic events \\
\hline \multirow[t]{5}{*}{ Trastuzumab } & \multirow[t]{5}{*}{ HER-2 (+) breast cancer } & Elderly & \multirow{2}{*}{$\begin{array}{l}\text { Defects in HER-2 signaling } \\
\text { associated with cardiac } \\
\text { contractility }\end{array}$} & Early \\
\hline & & Prior mediastinal irradiation & & $\mathrm{CHF}$ \\
\hline & & Underlying CV disease & \multirow{3}{*}{$\begin{array}{l}\text { Immune-mediated } \\
\text { destruction of cardiomyoytes } \\
\text { caused by selective binding } \\
\text { to HER-2 protein }\end{array}$} & LV dysfunction \\
\hline & & \multirow[t]{2}{*}{ Use with anthracyclines } & & Late \\
\hline & & & & Cardiomyopathy \\
\hline
\end{tabular}

$A M L$ acute myeloid leukemia, $A P L$ acute promyelocytic leukemia, $C A D$ coronary artery disease, $C H F$ congestive heart failure, $C M L$ chronic myeloid leukemia, $C V$ cardiovascular, EGFR epidermal growth factor receptor, ETC. electron transport chain, GIST gastrointestinal stromal tumor, HCC haptocellular carcinoma, HER human epidermal growth factor receptor 2, HTN hypertension, $L V$ left ventricle, $L V H$ left ventricular hypertrophy, NHL non-Hodgkin's lymphoma, $R C C$ renal cell carcinoma, $R O S$ reactive oxygen species, SCD sudden cardiac death, VEGF vascular endothelial growth factor.

cancer has been associated with subclinical deteriorations in left ventricular ejection fraction (LVEF) [36]. Piccart-Gebhart, et al. identified the incidence of clinical CHF or a subclinical deterioration of LVEF, defined as a decrease in LVEF by $10 \%$ [37], to be $1.7 \%$ and $7 \%$, respectively, in women receiving trastuzumab. In a separate study by Seidman, et al. cardiac dysfunction, defined as symptomatic CHF or an asymptomatic deterioration in LVEF of $10 \%$, occurred in $27 \%$ of women who received trastuzumab versus $8 \%$ receiving an anthracycline/cyclophosphamide combination [16]. Cardiac dysfunction with trastuzumab has been previously reported to occur in $13 \%$ of women as opposed to only $1 \%$ of women who received paclitaxel without trastuzumab [16].
Anthracycline cardiotoxicity appears to be potentiated by the concomitant administration of trastuzumab. This particular combination is associated with the development of severe LV systolic dysfunction, and as a result, these agents are now administered in series (as opposed to simultaneously) when utilized to treat breast cancer. Furthermore, some trials have shown that increasing the duration between anthracycline and trastuzumab administration reduces the incidence of LV dysfunction during treatment for breast cancer $[16,38]$.

\section{Hormone deprivation therapies}

In women with breast cancer or men with prostate cancer, the application of hormone deprivation therapies 
(aromatase inhibitors for post-menopausal women and gonadotropin releasing hormone $[\mathrm{GnRH}]$ agonists, antiandrogens, or orchiectomy in men) have dramatically improved cancer-related survival and reduced cancerrelated recurrence [39-42]. Importantly however, it is increasingly recognized that these therapies are associated with CV events $[43,44]$. Androgen deprivation therapy (ADT) is associated with the development of peripheral arterial disease (PAD) and cerebrovascular disease including stroke or transient ischemic attack (TIA) [45]. Among 182,757 men $>66$ years in age, ADT was associated with a 5-year increased incidence of PAD upon receipt of GnRH agonists (adjusted HR 1.16, 95\% CI 1.12-1.21) or after bilateral orchiectomy (adjusted HR 1.13, 95\% CI 1.02-1.26) [45]. Both therapeutic strategies were associated with an increase in venous thromboembolism (adjusted HR 1.10, 95\% CI 1.04-1.15; and adjusted HR 1.27, 95\% CI 1.11-1.45, respectively) [45]. Prior studies have reported that PAD develops shortly (as early as 1 to 4 months) after ADT initiation and is often accompanied by an increase in incident diabetes and serum lipoprotein abnormalities.

Multiple studies have confirmed an increased risk of stroke/TIA after receipt of GnRH agonists, oral antiandrogens or bilateral orchiectomy [46,47]. Among 22,310 men with prostate cancer followed for an average of 3.9 years, ADT use was associated with the development of stroke/TIA, specifically GnRH agonists (adjusted RR 1.18, 95\% CI 1.00-1.39), oral anti-androgens (adjusted RR 1.47 , 95\% CI 1.08-2.01), and those who underwent bilateral orchiectomy (adjusted RR 1.77, 95\% CI 1.25- 2.39) [48]. The risk was not modified based on the presence of underlying cardiac risk factors with the highest risk seen in men $<65$ years of age (adjusted HR 2.47, 95\% CI 1.24-4.47).

In post-menopausal women, the administration of aromatase inhibitors reduces breast cancer recurrence $[42,49]$. The etiology of this reduction is felt to be related to the severe reduction in circulating estrogens to near unmeasurable levels [40]. It is becoming increasingly recognized, however, that vascular disease and associated $\mathrm{CV}$ events are becoming more prevalent upon receipt of aromatase inhibitors. In a meta-analysis of seven trials that included 30,023 patients comparing aromatase inhibitors and tamoxifen, longer durations of aromatase inhibitor use was associated with increases in the odds ratios of developing CV disease (OR 1.26, 95\% CI 1.10-1.43, p < 0.001) [39].

In summary, for some individuals, traditional and newer therapeutic interventions for cancer (Table 1) can promote a variety of both cardiac (CHF) and vascular (MI, stroke, PAD) associated disorders. With the emergence of these disorders affecting multiple components of the CV system, there exists a unique opportunity to utilize imaging to both diagnose and guide therapeutic interventions to diagnose and then guide the administration of therapeutic interventions to prevent these untoward effects.

\section{Identification of cardiac toxicity}

For the heart, several strategies have been utilized to identify myocardial injury related to the administration for cancer [50]. Upon the first recognition of anthracyclinerelated myocardial dysfunction, endomyocardial biopsies were performed to identify histopathologic evidence of myofibrillar loss, vacuolization and extracellular loss [51,52] and thereby confirm or refute the presence of cardiotoxicity. Importantly however, this form of monitoring became impractical for widespread clinical application as the technique required an invasive procedure that was not well-suited for repetitive examinations [50].

In the 1970s and 1980s, serial multigated nuclear radioisotope studies or MUGA exams were serially implemented to detect LV systolic dysfunction in patients treated with anthracycline-based chemotherapy [53,54]. Evidence of deterioration in LVEF on MUGA scans during receipt of anthracycline chemotherapy was associated with the development of CHF $[53,55]$. Today, many of the existing management protocols rely on serial measures of LVEF by MUGA or transthoracic echocardiography to identify chemotherapy or immunotherapy induced reductions in LV ejection fraction [56,57]. Importantly however, distinguishing relatively small changes in LVEF related to cardiotoxicity from those related to variance in the technique can be problematic. As a result, more advanced transthoracic echocardiography (strain or diastolic function) assessments, [58] with or without concomitant serum biomarkers (such as serum troponin I levels $[59,60]$ ) have been utilized with a goal of increasing detection of early evidence of cardiac injury after chemotherapy $[61,62]$. The goal of these strategies is to identify those at risk of future $\mathrm{CV}$ events in order to implement therapy to prevent these events.

It is important to note, however, that difficulties remain with some of these newer quantitative strategies. Echocardiography can be difficult to reliably perform longitudinally over time due to body habitus, prior radiation treatment, or prosthetic implants, and therefore, it can be difficult to obtain adequate images from reproducible slice positions in a reliable fashion. While serum biomarkers can be easily acquired, these tests can lack specificity for cardiac injury related to the administration of therapy for cancer. Reduced specificity of identification of chemotherapy-related cardiac injury can lead to the unnecessary premature termination of chemotherapy that prevents an individual cancer patient from realizing the full benefit of his or her medical regimen.

Uniquely, CMR is well-suited to impact the detection of $\mathrm{CV}$ injury after receipt of cancer treatment. CMR does not incorporate ionizing radiation, thus is useful for repetitive evaluations [63]. During a single exam, both the heart and vasculature can be simultaneously assessed, an important feature when evaluating patients receiving multiple therapies that can promote injury to multiple components of the $\mathrm{CV}$ system, such as cardiomyocytes and arterial endothelial 
cells that can both experience mitochondrial dysfunction after the administration of anthracycline chemotherapy $[64,65]$. In addition, CMR can be utilized to detect multiple aspects of a disease process by characterizing tissue [66], measuring function [67], and identifying structural or metabolic abnormalities [58] that can be impacted by the treatment of cancer.

\section{CMR to detect $\mathrm{CV}$ related injury}

The role of CMR in identifying cardiotoxicity can be divided into 5 broad categories (Figure $1 \mathrm{~A}$ and $\mathrm{B}$ ):

(1) The detection of cardiac anatomic or structural abnormalities including valvular lesions, pericardial disease, or evidence of metastasis;

(2) The identification and surveillance of myocellular injury;

(3) The surveillance of ventricular function;

(4) The assessment of vascular injury; and

(5) The evaluation of skeletal muscle injury.

We discuss these categories in more detail in the sections below.

\section{Valvular and pericardial disease}

In addition to cardiomyopathy and development of CAD, valvular and pericardial involvement has also been identified as progressive complications occurring late (i.e. 15-20 years) after exposure to chemotherapy and radiation therapy [68]. Schellong, et al. have shown that in 1,132 survivors of Hodgkin's disease who received anthracycline and radiation before 18 years of age, valvular defects were diagnosed most frequently, followed by CAD, cardiomyopathies, conduction disorders, and pericardial abnormalities with median interval between therapy and onset of cardiac disease at 20 years. At 25 years post chemotherapy and radiation therapy, the cumulative incidence of cardiac disease was 0.14 , valvular disease was 0.09 and pericardial disease was 0.05 [69]. Aortic regurgitation was the most common abnormality identified in this cohort. Using echocardiography, in 116 patients, Wethal, et al. have identified 33\% progression of aortic regurgitation (defined as new onset of aortic regurgitation on follow-up, or increase by one grade of severity) and 39\% development of aortic stenosis over 12 years in young survivors (median age 22 years) of Hodgkin's lymphoma exposed to anthracyclines or radiation therapy. In a similar study of 1,249 survivors of Hodgkin's lymphoma, absolute excess risks of requiring valve replacement or pericardiectomy/pericardiocentesis were 14.1 and 4.7 per 10,000 person-years, respectively. Extremes of age (the very old and the very young) as well as male gender were predictors for these cardiac events [70].

\section{Cardiac and pericardiac metastases}

In addition to detection of valvular or pericardial anatomic abnormalities, CMR is useful in detecting tumor metastasis. While primary tumors involving the heart are relatively rare [71], metastatic involvement is not uncommon [65]. Metastases can occur through direct invasion, lymphatic or hematogenous spread, or transvenous extension [71]. Metastases to the heart and pericardium are identified at autopsy in $10 \%-12 \%$ of all patients with malignancies [71,72]. The most common cardiac manifestation is development of a pericardial effusion which occurs through direct invasion or lymphatic spread. Due to proximity, lung cancer is a common etiology of metastases to the heart and pericardium. In addition, breast tumors, malignant melanoma, renal cell carcinoma, mediastinal lymphomas, and leukemias can metastasize to the heart. While these are initially identified by echocardiography, CMR offers volumetric coverage of the entire heart and provides the necessary means to characterize the abnormal metastatic tissue through the use of cine imaging (see Additional file 1), T2 and T1 mapping, gadolinium enhanced perfusion, and late gadolinium enhancement as shown in Figure 2. These techniques facilitate the differentiation of a malignant tumor in comparison to a lipoma, thrombus or pericardial cyst.

\section{Myocellular injury}

Of all the chemotherapeutic agents, anthracyclines have been the most extensively studied in terms of myocardial histopathologic changes in the short and long-term. As shown by Billingham and Isner, et al. $[52,73]$ some individuals do not, whereas others do, exhibit evidence of myocellular injury (myofibrillar loss, myocyte vacuolization, cellular necrosis and perivascular and interstitial fibrosis) after anthracycline exposure. With myocyte loss and interstitial edema, there is an expansion of the myocardial extracellular space and thereby the volume of distribution of water. This leads to the prolongation of T1 and T2 and thus increased signal intensity on $\mathrm{T} 1$ and $\mathrm{T} 2$ weighted images and signal prolongation (in msec) on T1 and T2 maps.

Evidence that changes in T1 signal could be appreciated with CMR were identified as early as 1987 when Thompson, et al. reported changes in pre-contrast $\mathrm{T} 1 \mathrm{in}$ a model of chronic adriamycin cardiotoxicity (Table 2) [74]. These investigators identified a significant prolongation of pre-contrast $\mathrm{T} 1$ in an ex-vivo model of chronic adriamycin toxicity in rats. In these same animals, changes in $\mathrm{T} 2$ were absent. The results of this study also identified abnormalities in myocardial energy metabolism using P31 nuclear magnetic resonance [58]. In this chronic adriamycin toxicity model, hemodynamic stress in the form of rapid atrial pacing was administered. Decreased myocardial phosphocreatinine levels were noted after hemodynamic stress in both the adriamycin-treated and the control rats. 


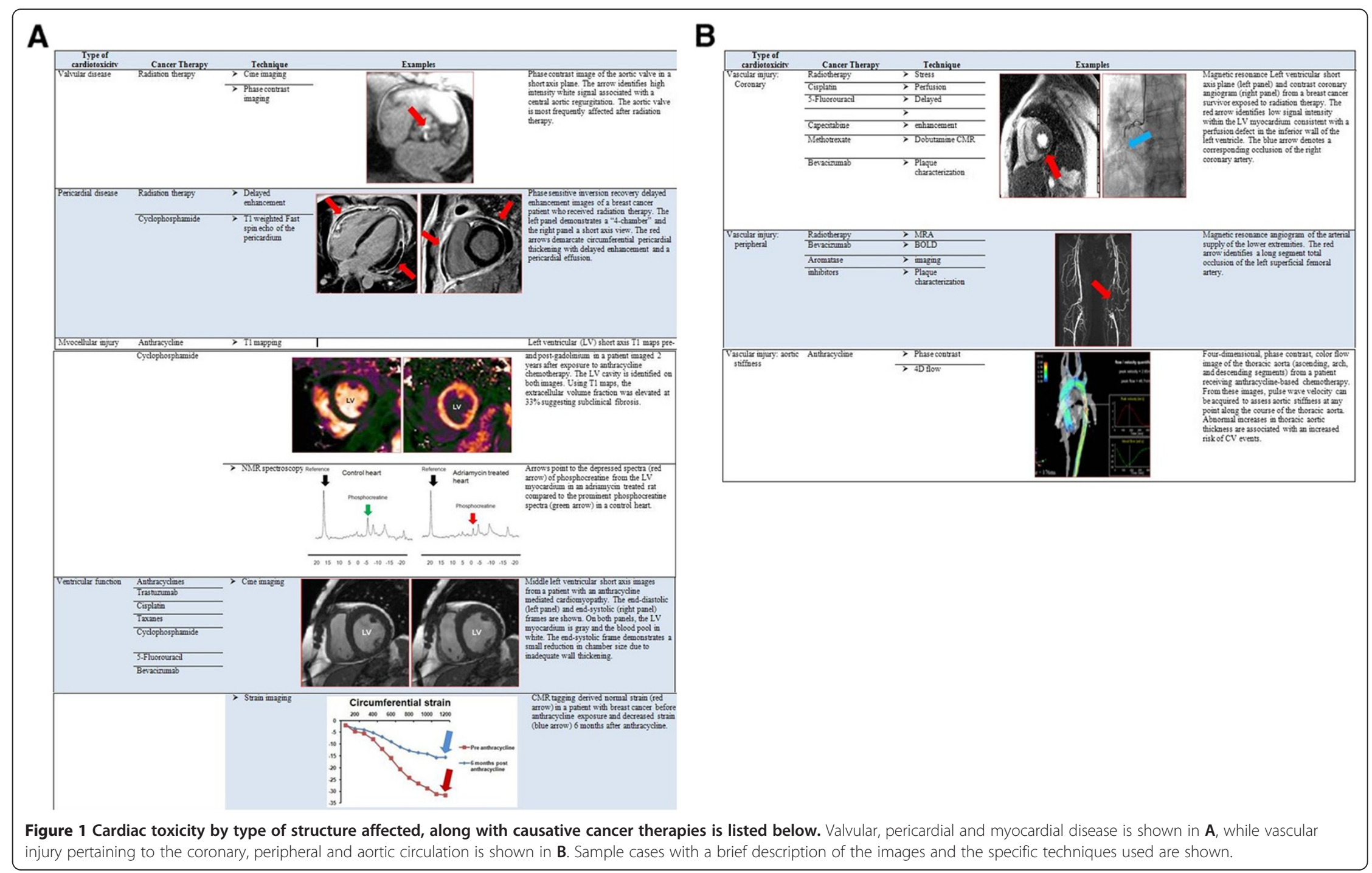



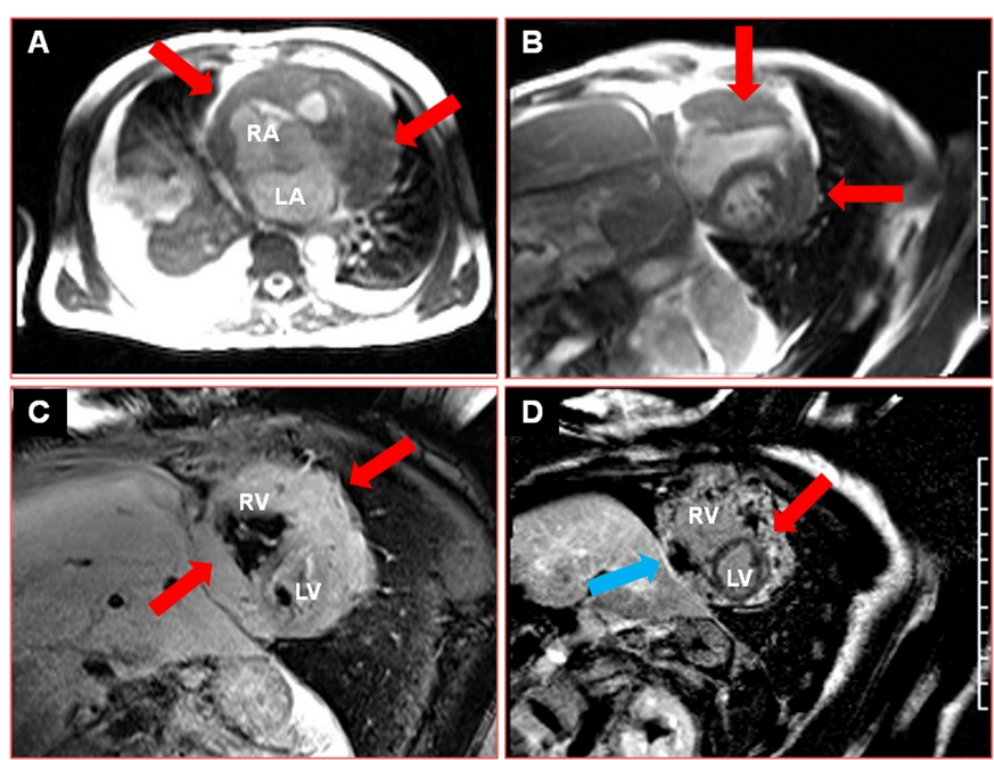

Figure 2 Imaging of cardiac metastases. Images from a patient with lung cancer with pericardial metastases. Panel A shows an axial slice of the heart acquired by steady-state free precession imaging. The red arrows point to the circumferential pericardial mass, which is hypointense and encases the entire right atrium, right ventricle and left ventricle. Panel $\mathbf{B}$ shows a cine image of the pericardial mass in a short-axis orientation (an additional movie file shows the cine series in motion [see Additional file 1]). In addition to the circumferential extent of the mass, the anterolateral wall of the left ventricle and the free wall of the right ventricle are tethered to the mass with reduced wall thickening and motion (arrows). Panel $\mathbf{C}$ shows a T2 weighted image in the same short-axis orientation. The red arrows point to the hyperintense mass. Panel $\mathbf{D}$ shows a delayed enhancement image of the mass in the short axis orientation. The red arrow points to the areas of hyperenhancement within the mass. The blue arrow points to the necrotic areas within the mass which are hypoenhanced with low signal intensity.

However, the adriamycin-treated rats experienced a delay and impartial recovery of the phosphocreatinine levels compared to controls. Thus after chronic receipt of adriamycin, both $\mathrm{T} 1$ tissue characteristics and cellular metabolism became abnormal after stress.

The observation of increased myocardial T1 on precontrast images was confirmed by Cottin, et al. as early as 1 week after administration of adriamycin (Table 2) [75]. This group also noted an increase in myocardial water content, and dissimilar to the Thompson results, an increase in T2, localized to the lateral free wall. These abnormalities occurred prior to deterioration in $\mathrm{LV}$ systolic performance. This group also identified abnormalities of lipid peroxidation concomitant with the observed increase in myocardial T1 and T2 signal.

Similarly, abnormalities in signal intensity on postcontrast T1 weighted images were noticed in human studies by Wassmuth, et al. [76]. This group of investigators used contrast enhanced spin echo in 22 patients who were imaged at 3 and 28 days after receipt of anthracycline chemotherapy. Higher myocardial signal intensities were noted as early as 3 days after receipt of anthracycline chemotherapy and predicted a future drop in the LVEF. Furthermore, patients who did not

Table 2 Changes in Myocardial signal characteristics after cancer treatment

\begin{tabular}{|c|c|c|c|c|c|}
\hline Study & Cancer therapy & $\begin{array}{l}\text { Myocardial signal } \\
\text { characterization }\end{array}$ & How assessed & $\begin{array}{l}\text { Subjects } \\
\text { (\# and type) }\end{array}$ & Findings \\
\hline $\begin{array}{l}\text { Thompson } \\
\text { et al. [74] }\end{array}$ & $\begin{array}{l}\text { Anthracycline chronic } \\
\text { toxicity }\end{array}$ & $\begin{array}{l}\text { T1 changes, no T2 } \\
\text { changes }\end{array}$ & Ex vivo spin echo & Rat model & Prolongation of pre-contrast T1. \\
\hline $\begin{array}{l}\text { Cottin } \\
\text { et al. [75] }\end{array}$ & $\begin{array}{l}\text { Anthracycline acute } \\
\text { toxicity, } 1 \text { week }\end{array}$ & $\mathrm{T} 1$ and $\mathrm{T} 2$ changes & $\begin{array}{l}\text { Ex vivo inversion recovery } \\
\text { for } T 1 \text {, spin echo for } T 2\end{array}$ & $\begin{array}{l}\text { Rat model, } \\
\mathrm{n}=23\end{array}$ & Prolongation of pre-contrast $\mathrm{T} 1$ and $\mathrm{T} 2$. \\
\hline $\begin{array}{l}\text { Wassmuth } \\
\text { et al. [76] }\end{array}$ & $\begin{array}{l}\text { Anthracycline acute } \\
\text { toxicity, Day } 3 \text { and } 28\end{array}$ & $\begin{array}{l}\text { T1 changes on } \\
\text { Day } 3\end{array}$ & $\begin{array}{l}\text { Contrast enhanced Spin } \\
\text { echo }\end{array}$ & $\begin{array}{l}\text { Humans, } \\
\mathrm{n}=79\end{array}$ & $\begin{array}{l}\text { Higher signal intensities on T1 weighted } \\
\text { imaging. }\end{array}$ \\
\hline \multirow[t]{2}{*}{$\begin{array}{l}\text { Lightfoot } \\
\text { et al. [77] }\end{array}$} & \multirow[t]{2}{*}{$\begin{array}{l}\text { Anthracycline, acute } \\
\text { toxicity at 2, 4, } 7 \text { and } \\
10 \text { weeks }\end{array}$} & \multirow[t]{2}{*}{$\begin{array}{l}\text { T1 changes at } \\
2 \text { weeks and } \\
4 \text { weeks }\end{array}$} & \multirow[t]{2}{*}{$\begin{array}{l}\text { Post-contrast } \mathrm{T} 1 \\
\text { weighted inversion } \\
\text { recovery }\end{array}$} & \multirow[t]{2}{*}{$\begin{array}{l}\text { Rat model, } \\
\mathrm{n}=40\end{array}$} & $\begin{array}{l}\text { Higher signal intensity than control rats. } \\
\text { This occurred early after chemotherapy and } \\
\text { prior to a drop in the LVEF. }\end{array}$ \\
\hline & & & & & $\begin{array}{l}\text { This increase in signal intensity was } \\
\text { associated with microscopic evidence of } \\
\text { cell injury. }\end{array}$ \\
\hline
\end{tabular}


experience contrast enhancement maintained their LVEF after receipt of anthracycline chemotherapy.

Subsequently, with the advent of inversion recovery gradient recalled echo (GRE) sequences and the ability to identify myocardial fibrosis with gadolinium contrast, a study was performed by Lightfoot, et al. with a larger number of animals to assess the changes in myocardial $\mathrm{T} 1$ after varying doses of the anthracycline doxorubicin (Table 2) [77]. The changes in signal intensity in post-contrast T1 weighted images in 40 rats exposed to two different doses of doxorubicin (1.5 and $2.5 \mathrm{mg} / \mathrm{kg} /$ week) were measured and compared to that from animals that received saline. Animals that experienced a drop in the LVEF after receipt of low or high doses of doxorubicin demonstrated higher mean signal intensity measured in the post-gadolinium $\mathrm{T} 1$ weighted inversion recovery images of the LV myocardium relative to those animals whose LVEF was maintained (Figure 3). Furthermore, increases in signal intensity during early measurement points were $80 \%$ sensitive and $82 \%$ specific for forecasting a future drop in LVEF. As shown in Figure 3, animals with higher signal intensities were found to have typical microscopic evidence of myocellular injury due to myocardial vacuolization and the accumulation of intra- and extracellular edema. Animals without cardiac dysfunction exhibited normal signal intensities and no histopathologic evidence of myocellular injury (Figure 3).
With myocyte loss and interstitial edema, there is an expansion of the myocardial extracellular space and hence the volume of distribution of gadolinium contrast. This enables incorporation of these T1 mapping techniques for assessment of diffuse myocardial fibrosis in routine clinical studies. While conventional delayed enhancement imaging is excellent for the detection of focal myocardial fibrosis, this requires nulling of the remaining myocardium rendering it more difficult to assess diffuse myocardial fibrosis. Multiple studies have confirmed the utility of T1 mapping before and after gadolinium to identify the myocardial partition coefficient of gadolinium and thereby the myocardial extracellular volume fraction (ECVF) [78-80]. Messroghli, et al. have developed accurate T1 mapping techniques to be performed in a single breathhold [81-83], and Flett, et al. have studied alternative T1 mapping techniques and found an excellent correlation between diffuse fibrosis and the histological collagen volume fraction in patients with myocardial hypertrophy due to aortic stenosis or hypertrophic cardiomyopathy [84]. In patients with cardiomyopathy, the myocardial ECVF assessment has prognostic value beyond assessment of LVEF [85]. Whether similar prognostic value of the myocardial ECVF can be assessed in cancer survivors is an area of ongoing study.

In summary, CMR has the potential to assess early cardiac injury by using T2 mapping and pre- and post-

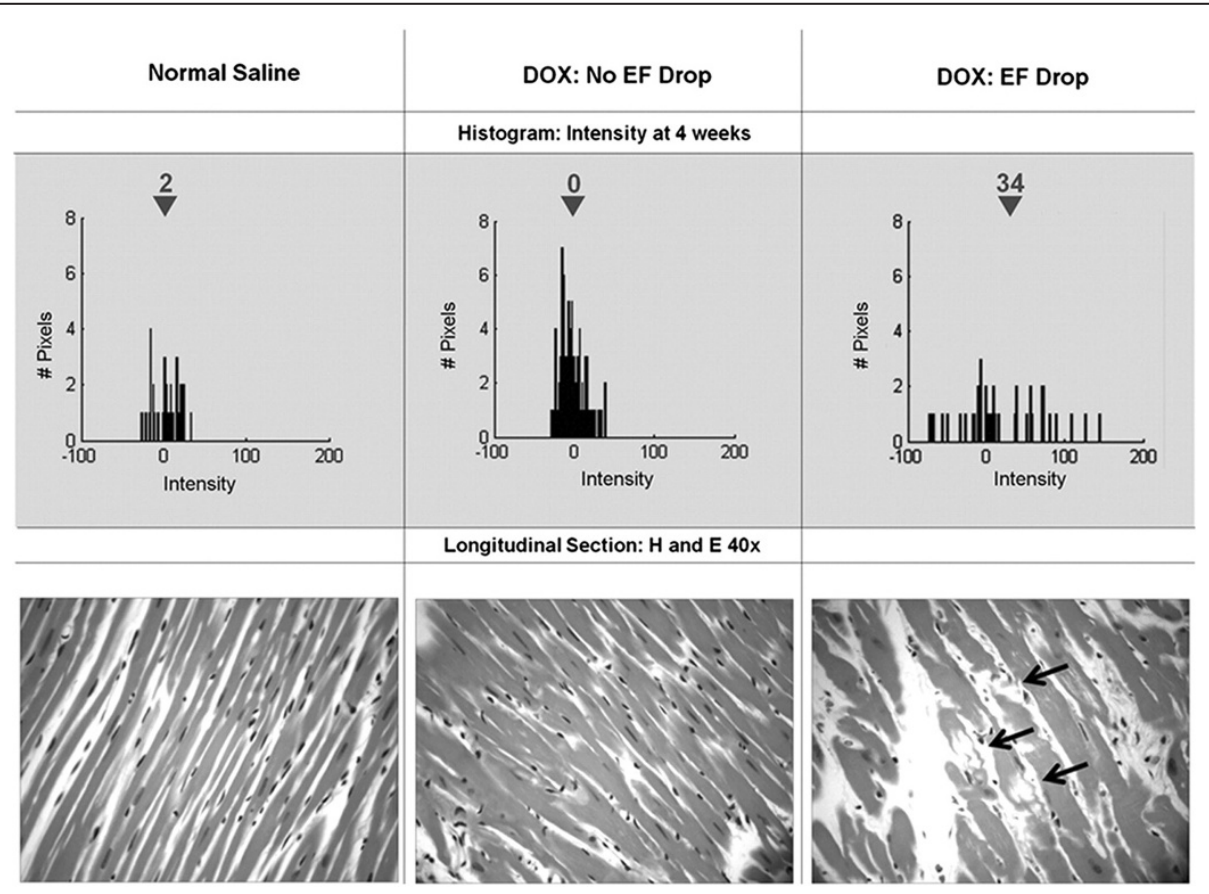

Figure 3 Correlation of T1 signal intensity change after anthracycline exposure with histopathologic changes in the myocardium. Serial histograms and histopathology of the myocardium before and after receipt of anthracycline. On the top portion of the figure are shown 4-week histograms of the number of pixels (y-axes) and intensities (x-axes) in individual animals after receipt of NS (top left), DOX without an EF drop (top middle), and DOX with an EF drop (top right). Below the histograms are 40x hematoxylin and eosin histopathologic images from the same animals. As shown, mean intensity increased in the animals that had a drop in EF corresponding to vacuolization (arrows, bottom right). Reprinted from Lightfoot, et al. Circ Cardiovasc Imaging 2010 [77]. 
contrast T1 mapping. This ability to identify myocardial abnormalities that precede functional impairment offers an opportunity to study the benefit of starting cardioprotective agents before overt functional deterioration.

\section{Ventricular function}

With the realization that evidence of myocardial injury due to the administration of anthracyclines could be appreciated during invasive endomyocardial biopsies or from diagnostic catheterization procedures, investigators sought to develop non-invasive methodologies to accomplish early detection of chemotherapy-related myocardial injury. In 1979, Alexander, et al. utilized quantitative, multi-gated radionuclide angiocardiography (or MUGA) scanning to serially assess LVEF in patients scheduled to receive doxorubicin for treatment of cancer. In a cohort of 55 individuals, a decline in LVEF by at least $15 \%$ to a final value of $<45 \%$ was associated with the development of CHF in patients receiving $>350 \mathrm{mg} / \mathrm{m}^{2}$ of anthracycline chemotherapy $[53,86]$. Soon thereafter, other investigators confirmed these findings [57].

As a result of these and other early non-invasive imaging studies, guidelines were published in 1992 that highlighted the use of LVEF measurements to screen and monitor patients for the development of cardiotoxicity and chemotherapy associated CHF $[57,86]$. These guidelines included an assessment of baseline LVEF prior to chemotherapy followed by subsequent LVEF measurements depending on the frequency and cumulative anthracycline dose prescribed. During serial surveillance, if a patient developed a deterioration in LVEF, then the risk of developing CHF was elevated and therapeutic interventions were suggested. It was also recognized that the surveillance strategy could be modified due to the presence of potential additional risk factors for anthracyclinebased myocardial injury. These risk factors included the application of mediastinal radiation, age (the very young and those with advanced age), pre-existing heart disease, and the associated administration of cyclophosphamide. Today, the majority of these early established guidelines are pervasive in the application of clinical care for patients that will receive anthracycline-based chemotherapy for the treatment of cancer.

Recent trials of newer cancer therapies that also promote cardiac injury such as trastuzumab, also routinely monitor LVEF with echocardiography or MUGA scanning to detect early deteriorations in LVEF that predispose one to develop CHF [36]. Guidelines have been published for the surveillance of LVEF during trastuzumab or other cancer therapies by the UK National Cancer Institute [87], and by the European Society of Medical Oncology [88]. In addition to baseline assessments of LVEF, additional assessments are recommended at 3 , 6, and 9 months after treatment with anthracyclines, and at 4 monthly intervals for trastuzumab.
Furthermore, the UK National Cancer Institute guidelines detail the use of a "traffic light" system to enable detection and management of cardiotoxicity with trastuzumab in which the therapeutic administration of angiotensin converting enzyme inhibitors is directed through measurement of LVEF.

CMR is well-suited to assess LVEF prior to and during receipt of potentially cardiotoxic chemotherapy. The ability to acquire images in multiple tomographic planes without limitations imposed by body habitus enable CMR LVEF assessments to be performed in patients who may have undergone prior surgery to pericardiac regions including the chest, lungs and mediastinum. Importantly, CMR accurately measures the ventricular volumes that contribute to the LVEF calculation. Compared with two-dimensional (2D) echocardiography, the inter-study coefficient of variability for assessment of LV volumes, function and mass was superior for CMR among healthy individuals, as well as those with heart failure or left ventricular hypertrophy [89]. The interstudy reproducibility for CMR measured end-systolic volume was $4.4 \%$ to $9.2 \%$ (versus 12.7 to $20.3 \%$ for $2 \mathrm{D}$ echocardiography), for ejection fraction was $2.4 \%$ to $7.3 \%$ (versus $8.6 \%$ to $9.4 \%$ for $2 \mathrm{D}$ echocardiography), and for LV mass was $2.8 \%$ to $4.8 \%$ (versus $11.6 \%$ to $15.7 \%$ for 2D echocardiography) [89]. Similarly, low inter-observer variability was noted in a comprehensive study comparing CMR volumes derived by cine and spin echo CMR [90]. Abnormalities of left ventricular end-diastolic volume (LVEDV), which could be due to changes in LV preload, can be detected with CMR. This LVEDV assessment is particularly important in patients receiving treatment for cancer who may exhibit altered pre-load due to poor oral intake or excessive nausea and vomiting. In addition, CMR can accurately identify abnormalities of left ventricular end-systolic volume (LVESV), which reflect abnormalities of myocardial contractility. Finally, the 3-dimensional acquisitions of these LV volumes and EF are very useful when cardiac function becomes reduced and the left ventricle assumes an abnormal shape that may differ from a prolate ellipsoid that is often assumed for the calculation of LVEF using a $2 \mathrm{D}$ technique.

In addition to determinations of $\mathrm{LV}$ volumes and $\mathrm{EF}$, other measures of LV systolic and diastolic function can be obtained during the same CMR examination. For example, myocardial strain, a unitless measure of myocardial deformation can be assessed during ventricular systole or during ventricular diastole (strain rate). Both of these measures may provide incremental diagnostic information relative to LV function [91]. These values have been useful in assessing and identifying individuals with abnormalities of LV function due to ischemic [92] and non-ischemic cardiomyopathies [93] as well as other 
infiltrative myocardial diseases such as systemic amyloidosis [94,95]. Recently, Drafts, et al. acquired serial assessments of LV volumes and myocardial strain to identify abnormalities of LV performance during receipt of anthracycline chemotherapy. In 55 individuals scheduled to receive an anthracycline-based chemotherapeutic regimen for leukemia, lymphoma, or breast cancer, Drafts, et al., found that measures of LV systolic performance (LVESV and myocardial strain) deteriorated early (even after the first dose) of the administration of anthracyclinebased chemotherapy (Figure 4) [96]. Moreover, these deteriorations remained present after the discontinuation of anthracycline chemotherapy. These data highlight the potential utility of CMR for identifying abnormalities of LV performance that indicate ongoing cardiac dysfunction due to toxicity from anthracycline-based regimens. Combining both these advanced functional measures with myocardial tissue characterization techniques (such as the mapping technologies mentioned previously) could provide a new strategy for identifying those at risk of $\mathrm{CHF}$ and thereby guide therapeutic interventions to reduce these risks. Currently, a large multi-center randomized trial is underway utilizing CMR to assess the efficacy of conventional heart failure drugs such as ACEIs and beta-blockers in patients receiving trastuzumab therapy for breast cancer [97].

In addition to myocardial strain and volume assessment, promising techniques being developed include diffusion tensor imaging for the identification of impaired myocardial mechanics, [98] for example, impaired torsion and spectroscopy for assessing abnormal myocardial metabolism [99]. These techniques are currently being studied in hypertrophic cardiomyopathy and could be potentially used in patients exposed to cancer therapies, to identify myocardial abnormalities prior to the onset of overt systolic dysfunction.

\section{Vascular injury}

It is important to recognize that in addition to the development of CHF, many treatments for cancer also predispose individuals to the development of $\mathrm{CV}$ events related to abnormalities of the vascular system. These $\mathrm{CV}$ events include the development of MI, PAD, and stroke. Several different cancer therapies have been shown to promote these vascular related events.

Hormonal therapy such as ADT is associated with an increased incidence of MI, PAD, and stroke [45,46,100]. Tyrosine kinase inhibitors such as bevacizumab, sorafinib and sunitinib promote hypertension [100-103]. Recently, Chaosuwannakit, et al. demonstrated that proximal aortic wall stiffness increased 3 months after receipt of anthracycline-based chemotherapy compared to age matched controls (Figure 5) [64]. Among the anthracyclinebased chemotherapy recipients, the increased aortic stiffness was noted even after controlling for factors such as age, gender, diabetes, hyperlipidemia and hypertension. The magnitude of the increase was equivalent to that associated with aging the CV system by $10-20$ years.

Two additional features of this increase in stiffness are noteworthy. First, this occurred soon after administration of chemotherapy and therefore is dissimilar to the more chronic causes of stiffening (e.g. atherosclerosis) more commonly observed. Recently, Eckman, et al. identified early histopathologic evidence of coronary artery microcirculatory endothelial damage in an animal model of anthracycline cardiotoxicity [104]. Perhaps endothelial damage to the vasa vasorum supply or on the luminal surface of the aorta contributed to the abrupt increase in aortic stiffening. Further research is needed in this area.

Second, the increases in aortic stiffening were not dose dependent. This finding suggests there may be thresholds of susceptibility to vascular dysfunction, and further
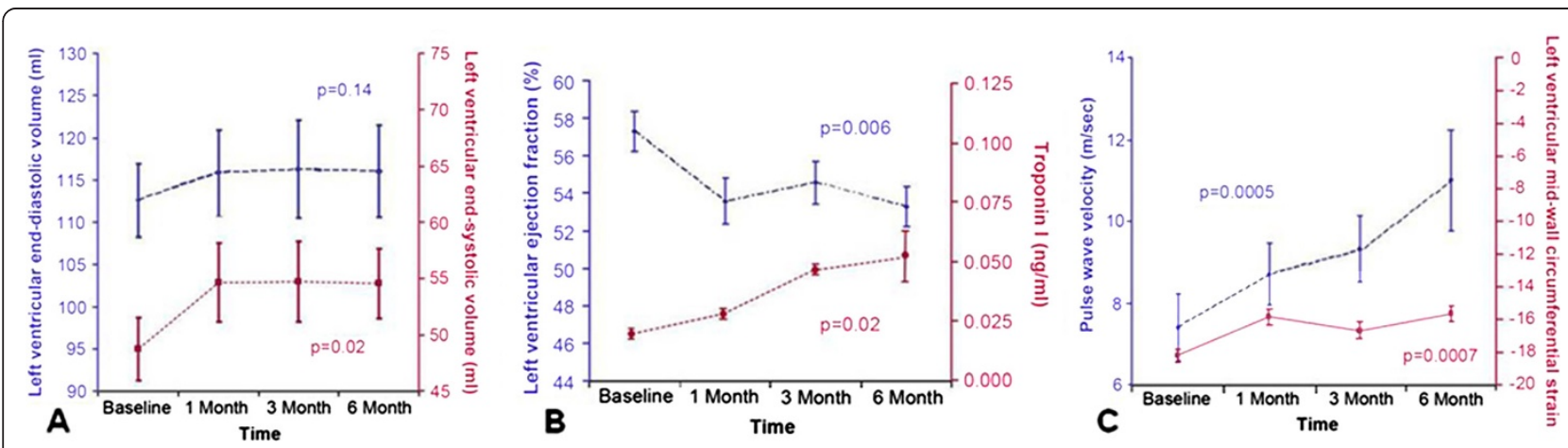

Figure 4 Serial changes in LV volumes, myocardial strain and LVEF after anthracycline exposure in human subjects. Time dependent changes in left ventricular (LV) end diastolic volume (left $y$-axis; panel $\mathbf{A}$ ) and LV end systolic volume (right $y$-axis; panel $\mathbf{A}$ ); in LV ejection fraction (left y-axis; panel B); serum Troponin-I (right y-axis; panel B); pulse wave velocity (PWV) (left y-axis; panel C); and mean mid wall circumferential strain (right $y$-axis; panel $\mathbf{C}$ ). The mean \pm the standard error are shown. There was a substantive increase in LV end systolic volume, PWV, and serum Troponin-I while at the same time a decrease in LV ejection fraction and mean mid-wall circumferential strain from baseline to six months after administration of low to moderate doses of anthracycline-based chemotherapy. Reprinted from Drafts, et al. JACC-Imaging 2012 [96]. 


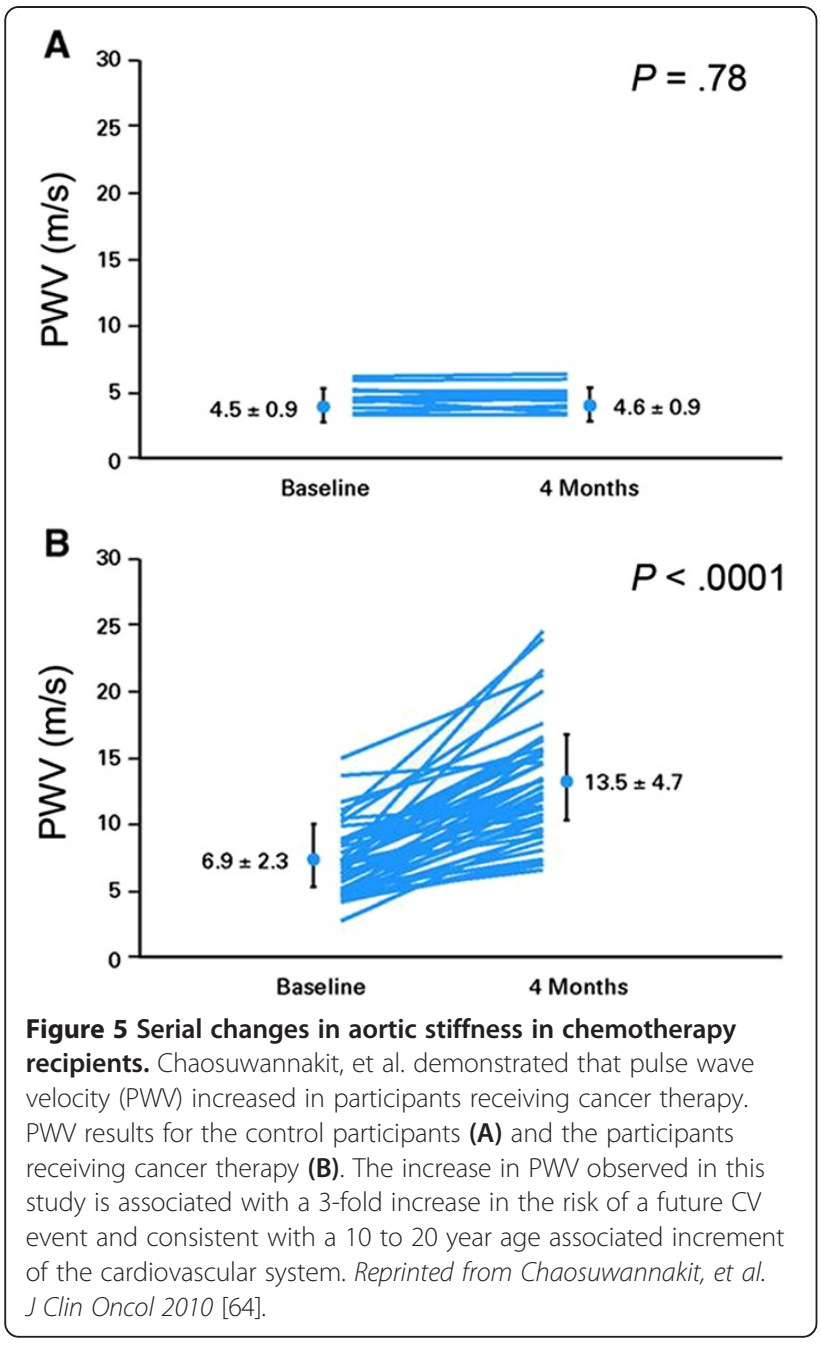

research may be useful in identifying these susceptibilities. These increases in aortic stiffness could have important clinical ramifications. Abnormal increases in proximal aortic stiffness have been associated with LV hypertrophy, exercise capacity (particular in the elderly) [105], and future CV events in those with diabetes, hypertension, renal failure, and advanced age. It is important to note, however, that it is unknown whether these increases in aortic stiffness are transient or whether they reverse after changes in therapy.

Additional changes to the vascular system have been reported upon receipt of treatment for cancer. These include the development of accelerated atherosclerosis and abnormalities of peripheral arterial endothelial function. In men treated for prostate cancer and post-menopausal women treated for breast cancer, the administration of ADT men and estrogen deprivation for women have been associated with the development of metabolic syndrome, diabetes, atherosclerosis, and $\mathrm{CV}$ events. Although not studied previously, there is potential for CMR to be used to identify the rapid progression of atherosclerosis by identifying abnormalities of aortic or carotid arterial wall thickness or the components of plaque composition (Figure 1B).

The administration of anthracycline-based chemotherapy has been associated with abnormalities of peripheral arterial and endothelial function. Endothelial function can be assessed noninvasively through the assessment of flow mediated arterial dilation (FMAD). CMR is highly advantageous for the assessment of peripheral arterial FMAD (Figure 1B). Phase contrast techniques that measure both wall shear stress and arterial dilation can be performed prior to, during, and after cuff inflation on both the upper as well as the lower extremity. These measures have been useful in identifying abnormalities of FMAD in older individuals with heart failure due to a reduced or preserved LVEF. At present, CMR FMAD measurements have not been acquired in patients treated for cancer. As the number of therapies targeted toward the vascular supply of tumors increases, the proven utility of CMR for assessing peripheral arterial endothelial function may be useful for identifying unintended injury to the native arterial circulation.

\section{Skeletal muscle function as a contributor to exercise capacity and fatigue}

Fatigue and muscle weakness are common among recipients of chemotherapy, and often they persist for many years after cessation of cancer treatment [106-108]. Perceived fatigue and weakness is debilitating with a profoundly negative impact on quality of life. In 33\% of women surviving treatment for breast cancer, fatigue is progressive and severely limits the ability to return to work [106]. In addition, fatigue may influence exercise capacity, a known predictor of CV events. Patients who received chemotherapy experience both fatigue and exercise intolerance, and therapeutic interventions that modify exercise capacity in cancer survivors also improve fatigue [109]. In fact, physical activity $>3$ METS is associated with reduced CV related morbidity and mortality in survivors of both breast and colon cancer $[110,111]$.

In those capable of normal ambulation, exercise capacity is influenced during stress by changes in cardiac output, arterial and microcirculatory function, and skeletal muscle metabolism and function. CMR is wellsuited to assess all three of these components of exercise capacity both at rest and during pharmacologic or exercise induced stress. In elderly patients with heart failure and preserved or reduced EF [112,113], CMR derived information from these three components has been utilized to understand mechanisms of disability and exercise intolerance. 
In addition to the cancer therapy mediated cardiac and vascular abnormalities identified in Table 1, skeletal muscle dysfunction may also occur after treatment for cancer. For example, doxorubicin potentiates direct skeletal muscle weakness through generation of reactive oxygen species and TNFa signaling [114]. Anthracyclines accumulate in skeletal muscle and have been shown to decrease muscle force on direct muscle force testing [115]. In addition they also cause loss of myofibrillar organization and interstitial edema [116]. To date, the role of the skeletal muscle weakness in exercise intolerance in chemotherapy recipients has not been systematically addressed; however, skeletal muscle energetics assessed at rest or after exercise with multinuclear spectroscopy could be highly informative in detecting abnormalities of ATP utilization that occur as a result of the impact of oxidative stress on the working mitochondria (Figure 1A). In addition, skeletal muscle oxygen uptake can be studied with novel blood oxygen level dependent (BOLD) MRI techniques. BOLD signaling relies on the hemoglobin oxygen saturation [117]. During increased tissue perfusion at constant levels of oxygen extraction, the oxyhemoglobin concentration is higher, and a lower concentration of paramagnetic deoxyhemoglobin is noted. This results in an increase in the T2 and T2* signal (positive BOLD signal). Coupling these BOLD assessments with measurements of skeletal muscle level microcirculatory perfusion after exercise using arterial spin labeling would be helpful to delineate muscle oxygen extraction for given levels of perfusion. In the calf of individuals with PAD, skeletal muscle phosphocreatine recovery after exercise has been shown to be diminished relative to control populations [118], and in combination with the measures of perfusion, oxygen utilization, and skeletal muscle mass, the incorporation of energetics could provide a more complete and quite novel understanding of the etiology of fatigue in cancer survivors (Figure 1A and B).

Future directions:

We have identified areas of research in cardiovascular toxicity beyond the assessment of cardiac structure and function, specifically to explore the mechanisms leading to co-morbidities that have a delayed onset after the initial exposure to cancer therapeutics. Table 3 provides a list of available newer MRI tools that can be utilized to assess the etiology of fatigue, accelerated atherosclerosis of the coronary, cerebral and peripheral vascular systems in addition to accelerated stiffness of the entire vascular system.

\section{Conclusion}

In summary, although cancer free survival is improving for many individuals treated for malignancies, an unintended consequence has been the emergence of cardiovascular events in the form of heart failure, myocardial infarction, stroke, and peripheral arterial disease. Temporally, it appears that these cardiovascular events and underlying subclinical cardiovascular disease are related to the therapies received for cancer. To this end, the ability of cardiovascular magnetic resonance to characterize and assess the function of the cardiovascular system is useful in identifying subclinical abnormalities of cardiovascular function that often precede CV events. Several single center studies have demonstrated the utility of CMR technologies to identify this early subclinical cardiovascular injury. Importantly however, further research is needed to fully develop cardiovascular magnetic procedures that both diagnose and also guide therapeutic interventions to prevent cardiovascular event and also the pronounced fatigue and related morbidities associated with administration of therapy for cancer.

Table 3 Unresolved issues in cancer survivors and possible techniques to address these issues

\begin{tabular}{|c|c|c|}
\hline Morbidity & Unresolved question & Proposed MRI technique \\
\hline Cerebro vascular accident & \multirow{3}{*}{ Accelerated atherosclerosis } & Wall thickness of ascending, descending aorta, plaque characterization \\
\hline Myocardial infarction & & Coronary flow reserve using quantitative myocardial perfusion \\
\hline Peripheral vascular disease & & Wall thickness of femoral arteries, BOLD imaging \\
\hline \multirow[t]{4}{*}{ LV systolic dysfunction } & \multirow{2}{*}{$\begin{array}{l}\text { Early detection of myocellular } \\
\text { injury and risk stratification }\end{array}$} & T1, T2 and ECV mapping \\
\hline & & Strain imaging \\
\hline & $\begin{array}{l}\text { Impairment of myocardial } \\
\text { mechanics, i.e. Impaired torsion }\end{array}$ & Diffusion tensor imaging \\
\hline & Myocardial energy metabolism & NMR P32 spectroscopy \\
\hline Impaired exercise tolerance & Arterial stiffness & 4D Flow for assessing pulse wave velocity \\
\hline \multirow[t]{2}{*}{ Fatigue } & \multirow[t]{2}{*}{ Skeletal muscle injury } & NMR spectroscopy to assess for mitochondrial dysfunction in skeletal muscle \\
\hline & & Fat/water separation to assess fat content \\
\hline Hypertension & Endothelial dysfunction & Flow mediated arterial dilation \\
\hline
\end{tabular}




\section{Additional file}

Additional file 1: Pericardial mass cineseries. Advanced Systems Format File (.asf) showing cine image of the pericardial mass in a shortaxis orientation.

\section{Competing interests}

Both authors declare thats they have no competing interests.

\section{Authors' contributions}

Both authors conceived the manuscript, performed the background research and review, and wrote and edited the text. Both authors read and approved the final manuscript.

\section{Acknowledgements}

Manuscript supported in part by NIH grants R01 HL076438, R01 CA167821, R33 CA121296, P30 AG21332, and T32 HL091824, and Susan G. Komen Foundation grant BCTR0707769.

Received: 12 April 2013 Accepted: 7 July 2013

Published: 31 July 2013

\section{References}

1. Bowles EJ, Wellman R, Feigelson HS, Onitilo AA, Freedman AN, Delate T, Allen LA, Nekhlyudov L, Goddard KA, Davis RL, et al. Risk of heart failure in breast cancer patients after anthracycline and trastuzumab treatment: a retrospective cohort study. J Natl Cancer Inst. 2012; 104:1293-305.

2. Brenner H. Long-term survival rates of cancer patients achieved by the end of the 20th century: a period analysis. Lancet. 2002; 360:1131-5.

3. Coughlin SS, Ekwueme DU. Breast cancer as a global health concern. Cancer Epidemiol. 2009; 33:315-8.

4. Du XL, Fox EE, Lai D. Competing causes of death for women with breast cancer and change over time from 1975 to 2003. Am J Clin Oncol. 2008; 31:105-16.

5. Geiger AM. Trastuzumab and congestive heart failure: what can we learn from use in the community? J Natl Cancer Inst. 2012; 104:1269-70.

6. Hooning MJ, Botma A, Aleman BM, Baaijens MH, Bartelink H, Klijn JG, Taylor CW, van Leeuwen FE. Long-term risk of cardiovascular disease in 10-year survivors of breast cancer. J Natl Cancer Inst. 2007; 99:365-75.

7. Maurea N, Coppola C, Ragone G, Frasci G, Bonelli A, Romano C, laffaioli RV. Women survive breast cancer but fall victim to heart failure: the shadows and lights of targeted therapy. J Cardiovasc Med (Hagerstown). 2010; 11:861-8.

8. Patnaik UL, Byers T, DiGuiseppi C, Dabelea D, Denberg TD. Cardiovascular disease competes with breast cancer as the leading cause of death for older females diagnosed with breast cancer: a retrospective cohort study. Breast Cancer Res. 2011; 13:R64.

9. Pinder MC, Duan Z, Goodwin JS, Hortobagyi GN, Giordano SH. Congestive heart failure in older women treated with adjuvant anthracycline chemotherapy for breast cancer. J Clin Oncol. 2007; 25:3808-15.

10. Schultz PN, Beck ML, Stava C, Vassilopoulou-Sellin R. Health profiles in 5836 long-term cancer survivors. Int J Cancer. 2003; 104:488-95.

11. Sukel MP, Breekveldt-Postma NS, Erkens JA, van der Linden PD, Beiderbeck $A B$, Coebergh JW, Herings RM. Incidence of cardiovascular events in breast cancer patients receiving chemotherapy in clinical practice. Pharmacoepidemiol Drug Saf. 2008; 17:125-34.

12. Yood MU, Wells KE, Alford SH, Dakki H, Beiderbeck AB, Hurria A, Gross CP, Oliveria SA. Cardiovascular outcomes in women with advanced breast cancer exposed to chemotherapy. Pharmacoepidemiol Drug Saf. 2012; 21:818-27.

13. SEER Cancer Statistics Review, 1975-2008. http://seer.cancer.gov/csr/ 1975_2008/, based on November 2010 SEER data submission, posted to the SEER web site, 2011.

14. Cancer Facts \& Figures 2012. http://www.cancer.org/acs/groups/content/ @epidemiologysurveilance/documents/document/acspc-031941.pdf.

15. Smith LA, Cornelius VR, Plummer CJ, Levitt G, Verrill M, Canney P, Jones A. Cardiotoxicity of anthracycline agents for the treatment of cancer: systematic review and meta-analysis of randomised controlled trials. BMC Cancer. 2010; 10:337.
16. Seidman A, Hudis C, Pierri MK, Shak S, Paton V, Ashby M, Murphy M, Stewart SJ, Keefe D. Cardiac dysfunction in the trastuzumab clinical trials experience. J Clin Oncol. 2002; 20:1215-21.

17. Keating NL, O'Malley AJ, Smith MR. Diabetes and cardiovascular disease during androgen deprivation therapy for prostate cancer. J Clin Oncol. 2006; 24(27):4448-56.

18. Pugh TJ, Ballonoff A, Rusthoven KE, McCammon R, Kavanagh B, Newman F, Rabinovitch R. Cardiac mortality in patients with stage I and II diffuse large B-cell lymphoma treated with and without radiation: a surveillance, epidemiology, and end-results analysis. Int J Radiat Oncol Biol Phys. 2010; 76:845-9.

19. Darby SC, Ewertz M, McGale P, Bennet AM, Blom-Goldman U, Brønnum D, Correa C, Cutter D, Gagliardi G, Gigante B, et al. Risk of ischemic heart disease in women after radiotherapy for breast cancer. $N$ Engl J Med. 2013; 368:987-98.

20. Meacham LR, Chow EJ, Ness KK, Kamdar KY, Chen Y, Yasui Y, Oeffinger KC, Sklar CA, Robison LL, Mertens AC. Cardiovascular risk factors in adult survivors of pediatric cancer-a report from the childhood cancer survivor study. Cancer Epidemiol Biomarkers Prev. 2010; 19:170-81.

21. Doyle JJ, Neugut Al, Jacobson JS, Grann VR, Hershman DL. Chemotherapy and cardiotoxicity in older breast cancer patients: a population-based study. J Clin Oncol. 2005; 23:8597-605.

22. Diller L, Chow EJ, Gurney JG, Hudson MM, Kadin-Lottick NS, Kawashima TI, Leisenring WM, Meacham LR, Mertens AC, Mulrooney DA, et al. Chronic disease in the childhood cancer survivor study cohort: a review of published findings. J Clin Oncol. 2009; 27:2339-55.

23. Guarneri V, Lenihan DJ, Valero V, Durand JB, Broglio K, Hess KR, Michaud LB, Gonzalez-Angulo AM, Hortobagyi GN, Esteva FJ. Long-term cardiac tolerability of trastuzumab in metastatic breast cancer: the M.D. Anderson Cancer Center experience. J Clin Oncol. 2006; 24:4107-15.

24. Mulrooney DA, Yeazel MW, Kawashima T, Mertens AC, Mitby P, Stovall M, Donaldson SS, Green DM, Sklar CA, Robison LL, Leisenring WM. Cardiac outcomes in a cohort of adult survivors of childhood and adolescent cancer: retrospective analysis of the Childhood Cancer Survivor Study cohort. BMJ. 2009; 339:b4606.

25. Perez EA, Rodeheffer R. Clinical cardiac tolerability of trastuzumab. J Clin Oncol. 2004; 22:322-9.

26. Steinberger J, Sinaiko AR, Kelly AS, Leisenring WM, Steffen LM, Goodman P, Mulrooney DA, Dietz AC, Moran A, Perkins JL, Baker KS. Cardiovascular risk and insulin resistance in childhood cancer survivors. J Pediatr. 2011; 160:494-9.

27. Swerdlow AJ, Higgins CD, Smith P, Cunningham D, Hancock BW, Horwich A, Hoskin PJ, Lister A, Radford JA, Rohatiner AZ, Linch DC. Myocardial infarction mortality risk after treatment for Hodgkin disease: a collaborative British cohort study. J Natl Cancer Inst. 2007; 99:206-14.

28. Ng AK, Bernardo MP, Weller E, Backstrand KH, Silver B, Marcus KC, Tarbell NJ, Friedberg J, Canellos GP, Mauch PM. Long-term survival and competing causes of death in patients with early-stage Hodgkin's disease treated at age 50 or younger. J Clin Oncol. 2002; 20:2101-8.

29. Bouchardy C, Rapiti E, Usel M, Majno SB, Vlastos G, Benhamou S, Miralbell R, Neyroud-Caspar I, Verkooijen HM, Vinh-Hung V. Excess of cardiovascular mortality among node-negative breast cancer patients irradiated for inner-quadrant tumors. Ann Oncol. 2010; 21:459-65.

30. Bouillon K, Haddy N, Delaloge S, Garbay JR, Garsi JP, Brindel P, Mousannif A, Lê MG, Labbe M, Arriagada R, et al. Long-term cardiovascular mortality after radiotherapy for breast cancer. J Am Coll Cardiol. 2011; 57:445-52

31. Curigliano G, Mayer EL, Burstein HJ, Winer EP, Goldhirsch A. Cardiac toxicity from systemic cancer therapy: a comprehensive review. Prog Cardiovasc Dis. 2010; 53:94-104.

32. Roychoudhuri R, Robinson D, Putcha V, Cuzick J, Darby S, Møller H. Increased cardiovascular mortality more than fifteen years after radiotherapy for breast cancer: a population-based study. BMC Cancer. 2007; 7:9.

33. Yeh ET, Bickford CL. Cardiovascular complications of cancer therapy: incidence, pathogenesis, diagnosis, and management. J Am Coll Cardiol. 2009; 53:2231-47.

34. Crone SA, Zhao YY, Fan L, Gu Y, Minamisawa S, Liu Y, Peterson KL, Chen J, Kahn R, Condorelli G, et al. ErbB2 is essential in the prevention of dilated cardiomyopathy. Nat Med. 2002; 8:459-65.

35. Slamon DJ, Leyland-Jones B, Shak S, Fuchs H, Paton V, Bajamonde A Fleming T, Eiermann W, Wolter J, Pegram M, et al. Use of chemotherapy 
plus a monoclonal antibody against HER2 for metastatic breast cancer that overexpresses HER2. N Engl J Med. 2001; 344:783-92.

36. Slamon D, Eiermann W, Robert N, Pienkowski T, Martin M, Press M, Mackey J, Glaspy J, Chan A, Pawlicki M, et al. Adjuvant trastuzumab in HER2positive breast cancer. N Engl J Med. 2011; 365:1273-83.

37. Piccart-Gebhart MJ, Procter M, Leyland-Jones B, Goldhirsch A, Untch M, Smith I, Gianni L, Baselga J, Bell R, Jackisch C, et al. Trastuzumab after adjuvant chemotherapy in HER2-positive breast cancer. N Engl J Med. 2005; 353:1659-72.

38. Tan-Chiu E, Yothers G, Romond E, Geyer CE Jr, Ewer M, Keefe D, Shannon RP, Swain SM, Brown A, Fehrenbacher L, et al. Assessment of cardiac dysfunction in a randomized trial comparing doxorubicin and cyclophosphamide followed by paclitaxel, with or without trastuzumab as adjuvant therapy in node-positive, human epidermal growth factor receptor 2-overexpressing breast cancer: NSABP B-31. J Clin Oncol. 2005; 23:7811-9.

39. Amir E, Seruga B, Niraula S, Carlsson L, Ocaña A. Toxicity of adjuvant endocrine therapy in postmenopausal breast cancer patients: a systematic review and meta-analysis. J Natl Cancer Inst. 2011; 103:1299-309.

40. Goss PE, Ingle JN, Martino S, Robert NJ, Muss HB, Piccart MJ, Castiglione M, Tu D, Shepherd LE, Pritchard KI, et al. A randomized trial of letrozole in postmenopausal women after five years of tamoxifen therapy for earlystage breast cancer. N Engl J Med. 2003; 349:1793-802.

41. Huggins C, Hodges CV. Studies on prostatic cancer: I. The effect of castration, of estrogen and of androgen injection on serum phosphatases in metastatic carcinoma of the prostate. 1941. J Urol. 2002; 168:9-12.

42. Thurlimann B, Keshaviah A, Coates AS, Mouridsen H, Mauriac L, Forbes JF, Paridaens R, Castiglione-Gertsch M, Gelber RD, Rabaglio M, et al. A comparison of letrozole and tamoxifen in postmenopausal women with early breast cancer. N Engl I Med. 2005; 353:2747-57.

43. Chapman JA, Meng D, Shepherd L, Parulekar W, Ingle JN, Muss HB, Palmer M, Yu C, Goss PE. Competing causes of death from a randomized trial of extended adjuvant endocrine therapy for breast cancer. J Natl Cancer Inst. 2008; 100:252-60.

44. Ewer MS, Gluck S. A woman's heart: the impact of adjuvant endocrine therapy on cardiovascular health. Cancer. 2009; 115:1813-26.

45. Hu JC, Williams SB, O'Malley AJ, Smith MR, Nguyen PL, Keating NL. Androgen-deprivation therapy for nonmetastatic prostate cancer is associated with an increased risk of peripheral arterial disease and venous thromboembolism. Eur Urol. 2012.

46. Keating NL, O'Malley AJ, Freedland SJ, Smith MR. Diabetes and cardiovascular disease during androgen deprivation therapy: observational study of veterans with prostate cancer. J Natl Cancer Inst. 2010; 102:39-46

47. Van Hemelrijck M, Garmo H, Holmberg L, Ingelsson E, Bratt O, Bill-Axelson A, Lambe M, Stattin P, Adolfsson J. Absolute and relative risk of cardiovascular disease in men with prostate cancer: results from the Population-Based PCBaSe Sweden. J Clin Oncol. 2010; 28:3448-56.

48. Azoulay L, Yin H, Benayoun S, Renoux C, Boivin JF, Suissa S. Androgendeprivation therapy and the risk of stroke in patients with prostate cancer. Eur Urol. 2011; 60:1244-50.

49. Buzdar A, Howell A, Cuzick J, Wale C, Distler W, Hoctin-Boes G, Houghton J, Locker GY, Nabholtz JM. Comprehensive side-effect profile of anastrozole and tamoxifen as adjuvant treatment for early-stage breast cancer: longterm safety analysis of the ATAC trial. Lancet Oncol. 2006; 7:633-43.

50. Meinardi MT, van der Graaf WT, van Veldhuisen DJ, Gietema JA, de Vries EG, Sleijfer DT. Detection of anthracycline-induced cardiotoxicity. Cancer Treat Rev. 1999; 25:237-47.

51. Billingham ME, Mason JW, Bristow MR, Daniels JR. Anthracycline cardiomyopathy monitored by morphologic changes. Cancer Treat Rep. 1978; 62:865-72

52. Isner JM, Ferrans VJ, Cohen SR, Witkind BG, Virmani R, Gottdiener JS, Beck JR, Roberts WC. Clinical and morphologic cardiac findings after anthracycline chemotherapy. Analysis of 64 patients studied at necropsy. Am J Cardiol. 1983; 51:1167-74.

53. Alexander J, Dainiak N, Berger HJ, Goldman L, Johnstone D, Reduto L, Duffy T, Schwartz P, Gottschalk A, Zaret BL. Serial assessment of doxorubicin cardiotoxicity with quantitative radionuclide angiocardiography. $\mathrm{N}$ Engl J Med. 1979; 300:278-83.
54. McKillop JH, Bristow MR, Goris ML, Billingham ME, Bockemuehl K. Sensitivity and specificity of radionuclide ejection fractions in doxorubicin cardiotoxicity. Am Heart J. 1983; 106:1048-56.

55. Gottdiener JS, Mathisen DJ, Borer JS, Bonow RO, Myers CE, Barr LH, Schwartz DE, Bacharach SL, Green MV, Rosenberg SA. Doxorubicin cardiotoxicity: assessment of late left ventricular dysfunction by radionuclide cineangiography. Ann Intern Med. 1981; 94:430-5.

56. Shankar SM, Marina N, Hudson MM, Hodgson DC, Adams MJ, Landier W, Bhatia S, Meeske K, Chen MH, Kinahan KE, et al. Monitoring for cardiovascular disease in survivors of childhood cancer: report from the cardiovascular disease task force of the children's oncology group. Pediatrics. 2008; 121:e387-96.

57. Steinherz LJ, Graham T, Hurwitz R, Sondheimer HM, Schwartz RG, Shaffer EM, Sandor G, Benson L, Williams R. Guidelines for cardiac monitoring of children during and after anthracycline therapy: report of the cardiology committee of the childrens cancer study group. Pediatrics. 1992; 89:942-9.

58. Bittner V, Reeves RC, Digerness SB, Caulfield JB, Pohost GM. 31P NMR spectroscopy in chronic adriamycin cardiotoxicity. Magn Reson Med. 1991; 17:69-81.

59. Cardinale D, Lamantia G, Cipolla CM. Troponin I and cardiovascular risk stratification in patients with testicular cancer. J Clin Oncol. 2006; 24:3508-9.

60. Cardinale D, Salvatici M, Sandri MT. Review: role of biomarkers in cardioncology. Clin Chem Lab Med. 2011; 49:1937-48.

61. Cardinale D, Colombo A, Cipolla CM. Prevention and treatment of cardiomyopathy and heart failure in patients receiving cancer chemotherapy. Curr Treat Options Cardiovasc Med. 2008; 10:486-95.

62. Cardinale D, Colombo A, Sandri MT, Lamantia G, Colombo N, Civelli M, Martinelli G, Veglia F, Fiorentini C, Cipolla CM. Prevention of high-dose chemotherapy-induced cardiotoxicity in high-risk patients by angiotensin-converting enzyme inhibition. Circulation. 2006; 114:2474-81.

63. Hendel RC, Patel MR, Kramer CM, Poon M, Carr JC, Gerstad NA, Gillam LD, Hodgson JM, Kim RJ, Lesser JR, et al. ACCF/ACR/SCCT/SCMR/ASNC/NASCl/ SCAI/SIR 2006 appropriateness criteria for cardiac computed tomography and cardiac magnetic resonance imaging: a report of the American College of Cardiology Foundation Quality Strategic Directions Committee Appropriateness Criteria Working Group, American College of Radiology, Society of Cardiovascular Computed Tomography, Society for Cardiovascular Magnetic Resonance, American Society of Nuclear Cardiology, North American Society for Cardiac Imaging, Society for Cardiovascular Angiography and Interventions, and Society of Interventional Radiology. J Am Coll Cardiol. 2006; 48:1475-97.

64. Chaosuwannakit N, D'Agostino R Jr, Hamilton CA, Lane KS, Ntim WO, Lawrence J, Melin SA, Ellis LR, Torti FM, Little WC, Hundley WG. Aortic stiffness increases upon receipt of anthracycline chemotherapy. J Clin Oncol. 2010; 28:166-72.

65. Pennell DJ, Sechtem UP, Higgins CB, Manning WJ, Pohost GM, Rademakers FE, van Rossum AC, Shaw $L$, Yucel EK. Clinical indications for cardiovascular magnetic resonance (CMR): Consensus Panel report. J Cardiovasc Magn Reson. 2004; 6:727-65.

66. Fallah-Rad N, Walker JR, Wassef A, Lytwyn M, Bohonis S, Fang T, Tian G, Kirkpatrick ID, Singal PK, Krahn M, et al. The utility of cardiac biomarkers, tissue velocity and strain imaging, and cardiac magnetic resonance imaging in predicting early left ventricular dysfunction in patients with human epidermal growth factor receptor II-positive breast cancer treated with adjuvant trastuzumab therapy. J Am Coll Cardiol. 2011; 57:2263-70

67. Banchs J, Jefferies JL, Plana JC, Hundley WG. Imaging for cardiotoxicity in cancer patients. Tex Heart Inst J. 2011; 38:268-9.

68. Adams MJ, Hardenbergh PH, Constine LS, Lipshultz SE. Radiationassociated cardiovascular disease. Crit Rev Oncol Hematol. 2003; 45:55-75

69. Schellong G, Riepenhausen M, Bruch C, Kotthoff S, Vogt J, Bolling T, Dieckmann K, Potter R, Heinecke A, Bramswig J, Dorffel W. Late valvular and other cardiac diseases after different doses of mediastinal radiotherapy for Hodgkin disease in children and adolescents: report from the longitudinal GPOH follow-up project of the German-Austrian DAL-HD studies. Pediatr Blood Cancer. 2010; 55:1145-52.

70. Galper SL, Yu JB, Mauch PM, Strasser JF, Silver B, Lacasce A, Marcus KJ, Stevenson MA, Chen MH, Ng AK. Clinically significant cardiac disease in patients with Hodgkin lymphoma treated with mediastinal irradiation. Blood. 2011: 117:412-8. 
71. Chiles C, Woodard PK, Gutierrez FR, Link KM. Metastatic involvement of the heart and pericardium: CT and MR imaging. Radiographics. 2001; 21:439-49

72. Abraham KP, Reddy V, Gattuso P. Neoplasms metastatic to the heart: review of 3314 consecutive autopsies. Am J Cardiovasc Pathol. 1990; 3:195-8.

73. Mason JW, Bristow MR, Billingham ME, Daniels JR. Invasive and noninvasive methods of assessing adriamycin cardiotoxic effects in man: superiority of histopathologic assessment using endomyocardial biopsy. Cancer Treat Rep. 1978; 62:857-64.

74. Thompson RC, Canby RC, Lojeski EW, Ratner AV, Fallon JT, Pohost GM Adriamycin cardiotoxicity and proton nuclear magnetic resonance relaxation properties. Am Heart J. 1987; 113:1444-9.

75. Cottin Y, Ribuot C, Maupoil V, Godin D, Arnould L, Brunotte F, Rochette L. Early incidence of adriamycin treatment on cardiac parameters in the rat. Can J Physiol Pharmacol. 1994; 72:140-5.

76. Wassmuth R, Lentzsch S, Erdbruegger U, Schulz-Menger J, Doerken B, Dietz R, Friedrich MG. Subclinical cardiotoxic effects of anthracyclines as assessed by magnetic resonance imaging-a pilot study. Am Heart J. 2001; 141:1007-13.

77. Lightfoot JC, D'Agostino RB Jr, Hamilton CA, Jordan J, Torti FM, Kock ND, Workman S, Hundley WG. Novel approach to early detection of doxorubicin cardiotoxicity by gadolinium-enhanced cardiovascular magnetic resonance imaging in an experimental model. Circ Cardiovasc Imaging. 2010; 3:550-8

78. Broberg CS, Chugh SS, Conklin C, Sahn DJ, Jerosch-Herold M. Quantification of diffuse myocardial fibrosis and its association with myocardial dysfunction in congenital heart disease. Circ Cardiovasc Imaging. 2010; 3:727-34.

79. Jerosch-Herold M, Sheridan DC, Kushner JD, Nauman D, Burgess D, Dutton D, Alharethi R, Li D, Hershberger RE. Cardiac magnetic resonance imaging of myocardial contrast uptake and blood flow in patients affected with idiopathic or familial dilated cardiomyopathy. Am J Physiol Heart Circ Physiol. 2008; 295:H1234-42.

80. Schelbert EB, Testa SM, Meier CG, Ceyrolles WJ, Levenson JE, Blair AJ Kellman $\mathrm{P}$, Jones BL, Ludwig DR, Schwartzman D, et al. Myocardial extravascular extracellular volume fraction measurement by gadolinium cardiovascular magnetic resonance in humans: slow infusion versus bolus. J Cardiovasc Magn Reson. 2011; 13:16.

81. Messroghli DR, Greiser A, Fröhlich M, Dietz R, Schulz-Menger J. Optimization and validation of a fully-integrated pulse sequence for modified look-locker inversion-recovery (MOLLI) T1 mapping of the heart. J Magn Reson Imaging. 2007; 26:1081-6.

82. Messroghli DR, Plein S, Higgins DM, Walters K, Jones TR, Ridgway JP, Sivananthan MU. Human myocardium: single-breath-hold MR T1 mapping with high spatial resolution-reproducibility study. Radiology. 2006; 238:1004-12

83. Messroghli DR, Radjenovic A, Kozerke S, Higgins DM, Sivananthan MU, Ridgway JP. Modified Look-Locker inversion recovery (MOLLI) for highresolution T1 mapping of the heart. Magn Reson Med. 2004; 52:141-6.

84. Flett AS, Hayward MP, Ashworth MT, Hansen MS, Taylor AM, Elliott PM, McGregor C, Moon JC. Equilibrium contrast cardiovascular magnetic resonance for the measurement of diffuse myocardial fibrosis: preliminary validation in humans. Circulation. 2010; 122:138-44.

85. Wong TC, Piehler K, Puntil KS, Moguillansky D, Meier CG, Lacomis JM, Kellman P, Cook SC, Schwartzman DS, Simon MA, et al. Effectiveness of late gadolinium enhancement to improve outcomes prediction in patients referred for cardiovascular magnetic resonance after echocardiography. J Cardiovasc Magn Reson. 2013; 15:6.

86. Schwartz RG, McKenzie WB, Alexander J, Sager P, D'Souza A, Manatunga A, Schwartz PE, Berger HJ, Setaro J, Surkin L, et al. Congestive heart failure and left ventricular dysfunction complicating doxorubicin therapy. Seven-year experience using serial radionuclide angiocardiography. Am J Med. 1987; 82:1109-18.

87. Jones AL, Barlow M, Barrett-Lee PJ, Canney PA, Gilmour IM, Robb SD, Plummer CJ, Wardley AM, Verrill MW. Management of cardiac health in trastuzumab-treated patients with breast cancer: updated United Kingdom National Cancer Research Institute recommendations for monitoring. Br J Cancer. 2009; 100:684-92.

88. Bovelli D, Plataniotis G, Roila F. Cardiotoxicity of chemotherapeutic agents and radiotherapy-related heart disease: ESMO Clinical Practice Guidelines. Ann Oncol. 2010; 21(Suppl 5):v277-82.
89. Grothues F, Smith GC, Moon JC, Bellenger NG, Collins P, Klein HU, Pennell DJ. Comparison of interstudy reproducibility of cardiovascular magnetic resonance with two-dimensional echocardiography in normal subjects and in patients with heart failure or left ventricular hypertrophy. Am J Cardiol. 2002; 90:29-34.

90. Pattynama PM, Lamb HJ, van der Velde EA, van der Wall EE, de Roos A. Left ventricular measurements with cine and spin-echo MR imaging: a study of reproducibility with variance component analysis. Radiology. 1993; 187:261-8.

91. Stoodley PW, Richards DA, Hui R, Boyd A, Harnett PR, Meikle SR, Clarke J, Thomas $L$. Two-dimensional myocardial strain imaging detects changes in left ventricular systolic function immediately after anthracycline chemotherapy. Eur J Echocardiogr. 2011; 12:945-52.

92. Motoki H, Borowski AG, Shrestha K, Troughton RW, Tang WH, Thomas JD, Klein AL. Incremental prognostic value of assessing left ventricular myocardial mechanics in patients with chronic systolic heart failure. J Am Coll Cardiol. 2012; 60:2074-81.

93. Cho GY, Marwick TH, Kim HS, Kim MK, Hong KS, Oh DJ. Global 2dimensional strain as a new prognosticator in patients with heart failure. J Am Coll Cardiol. 2009; 54:618-24.

94. Bellavia D, Abraham RS, Pellikka PA, Dispenzieri A, Burnett JC Jr, Al-Zahrani GB, Green TD, Manske MK, Gertz MA, Miller FA Jr, Abraham TP. Utility of Doppler myocardial imaging, cardiac biomarkers, and clonal immunoglobulin genes to assess left ventricular performance and stratify risk following peripheral blood stem cell transplantation in patients with systemic light chain amyloidosis (Al). J Am Soc Echocardiogr. 2011; 24:444-54.

95. Saito M, Okayama H, Yoshii T, Higashi H, Morioka H, Hiasa G, Sumimoto T, Inaba S, Nishimura K, Inoue K, et al. Clinical significance of global twodimensional strain as a surrogate parameter of myocardial fibrosis and cardiac events in patients with hypertrophic cardiomyopathy. Eur Heart J Cardiovasc Imaging. 2012; 13:617-23.

96. Drafts BC, Twomley KM, D'Agostino RB, Lawrence JA, Avis NE, Ellis LR, Thohan V, Jordan J, Melin SA, Torti FM, et al. Low to moderate dose anthracyline-based chemotherapy is associated with early noninvasive imaging evidence of subclinical cardiovascular disease. JACC CardiovasC Imaging. 2012: . doi:10.1016/j.jcmg.2012.11.017. Accepted for publication.

97. Pituskin E, Haykowsky M, Mackey JR, Thompson RB, Ezekowitz J, Koshman S, Oudit G, Chow K, Pagano JJ, Paterson I. Rationale and design of the Multidisciplinary Approach to Novel Therapies in Cardiology Oncology Research Trial (MANTICORE 101-Breast): a randomized, placebocontrolled trial to determine if conventional heart failure pharmacotherapy can prevent trastuzumab-mediated left ventricular remodeling among patients with HER2+ early breast cancer using cardiac MRI. BMC Cancer. 2011; 11:318.

98. McGill LA, Ismail TF, Nielles-Vallespin S, Ferreira P, Scott AD, Roughton M, Kilner PJ, Ho SY, McCarthy KP, Gatehouse PD, et al. Reproducibility of invivo diffusion tensor cardiovascular magnetic resonance in hypertrophic cardiomyopathy. J Cardiovasc Magn Reson. 2012; 14:86.

99. Rider OJ, Francis JM, Tyler D, Byrne J, Clarke K, Neubauer S. Effects of weight loss on myocardial energetics and diastolic function in obesity. Int J Cardiovasc Imaging. 2013; 29(5):1043-50. doi:10.1007/s10554-012-0174-6.

100. Saigal CS, Gore JL, Krupski TL, Hanley J, Schonlau M, Litwin MS. Androgen deprivation therapy increases cardiovascular morbidity in men with prostate cancer. Cancer. 2007; 110:1493-500.

101. Chu TF, Rupnick MA, Kerkela R, Dallabrida SM, Zurakowski D, Nguyen L, Woulfe K, Pravda E, Cassiola F, Desai J, et al. Cardiotoxicity associated with tyrosine kinase inhibitor sunitinib. Lancet. 2007; 370:2011-9.

102. Escudier B, Eisen T, Stadler WM, Szczylik C, Oudard S, Staehler M, Negrier S, Chevreau C, Desai AA, Rolland F, et al. Sorafenib for treatment of renal cell carcinoma: final efficacy and safety results of the phase III treatment approaches in renal cancer global evaluation trial. J Clin Oncol. 2009; 27:3312-8.

103. Miller K, Wang M, Gralow J, Dickler M, Cobleigh M, Perez EA, Shenkier T, Cella D, Davidson NE. Paclitaxel plus bevacizumab versus paclitaxel alone for metastatic breast cancer. N Engl J Med. 2007; 357:2666-76.

104. Eckman DM, Stacey RB, Rowe R, D. Agostino RJ, Kock ND, Sane DC, Torti FM, Yeboah J, Workman S, Lane KS, Hundley WG. Weekly Doxorubicin increases coronary arteriolar wall and adventitial thickness. PLoS One. 2013; 8:e57554.

105. Rerkpattanapipat $P$, Hundley WG, Link KM, Brubaker PH, Hamilton CA, Darty SN, Morgan TM, Kitzman DW. Relation of aortic distensibility determined 
by magnetic resonance imaging in patients $>$ or $=60$ years of age to systolic heart failure and exercise capacity. Am J Cardiol. 2002; 90:1221-5.

106. Meeske K, Smith AW, Alfano CM, McGregor BA, McTiernan A, Baumgartner $K B$, Malone KE, Reeve BB, Ballard-Barbash R, Bernstein L. Fatigue in breast cancer survivors two to five years post diagnosis: a HEAL Study report. Qual Life Res. 2007; 16:947-60.

107. Pater JL, Loeb M. Nonanatomic prognostic factors in carcinoma of the lung: a multivariate analysis. Cancer. 1982; 50:326-31.

108. Ringdal Gl, Gotestam KG, Kaasa S, Kvinnsland S, Ringdal K. Prognostic factors and survival in a heterogeneous sample of cancer patients. Br J Cancer. 1996; 73:1594-9.

109. Andersen C, Rørth M, Ejlertsen B, Stage M, Møller T, Midtgaard J, Quist M, Bloomquist $K$, Adamsen $L$. The effects of a six-week supervised multimodal exercise intervention during chemotherapy on cancerrelated fatigue. Eur J Oncol Nurs. 2013; 17(3):331-9. doi:10.1016/j. ejon.2012.09.003.

110. Holmes MD, Chen WY, Feskanich D, Kroenke CH, Colditz GA. Physical activity and survival after breast cancer diagnosis. JAMA. 2005; 293:2479-86.

111. Meyerhardt JA, Giovannucci EL, Holmes MD, Chan AT, Chan JA, Colditz GA, Fuchs CS. Physical activity and survival after colorectal cancer diagnosis. J Clin Oncol. 2006; 24:3527-34.

112. Hundley WG, Bayram E, Hamilton CA, Hamilton EA, Morgan TM, Darty SN, Stewart KP, Link KM, Herrington DM, Kitzman DW. Leg flow-mediated arterial dilation in elderly patients with heart failure and normal left ventricular ejection fraction. Am J Physiol Heart Circ Physiol. 2007; 292:H1427-34

113. Puntawangkoon C, Kitzman DW, Kritchevsky SB, Hamilton CA, Nicklas B, Leng X, Brubaker PH, Hundley WG. Reduced peripheral arterial blood flow with preserved cardiac output during submaximal bicycle exercise in elderly heart failure. J Cardiovasc Magn Reson. 2009; 11:48.

114. Gilliam LA, Ferreira LF, Bruton JD, Moylan JS, Westerblad H, St Clair DK, Reid MB. Doxorubicin acts through tumor necrosis factor receptor subtype 1 to cause dysfunction of murine skeletal muscle. J Appl Physiol. 2009; 107:1935-42.

115. Gilliam LA, Moylan JS, Ann Callahan L, Sumandea MP, Reid MB. Doxorubicin causes diaphragm weakness in murine models of cancer chemotherapy. Muscle Nerve. 2011: 43:94-102.

116. Doroshow JH, Tallent C, Schechter JE. Ultrastructural features of Adriamycin-induced skeletal and cardiac muscle toxicity. Am J Pathol. 1985; 118:288-97.

117. Jacobi B, Bongartz G, Partovi S, Schulte AC, Aschwanden M, Lumsden AB, Davies MG, Loebe M, Noon GP, Karimi S, et al. Skeletal muscle BOLD MRI: from underlying physiological concepts to its usefulness in clinical conditions. J Magn Reson Imaging. 2012; 35:1253-65.

118. Ledermann HP, Heidecker HG, Schulte AC, Thalhammer C, Aschwanden M Jaeger KA, Scheffler K, Bilecen D. Calf muscles imaged at BOLD MR: correlation with TcPO2 and flowmetry measurements during ischemia and reactive hyperemia-initial experience. Radiology. 2006; 241:477-84.

doi:10.1186/1532-429X-15-66

Cite this article as: Vasu and Hundley: Understanding cardiovascular injury after treatment for cancer: an overview of current uses and future directions of cardiovascular magnetic resonance. Journal of Cardiovascular Magnetic Resonance 2013 15:66.

\section{Submit your next manuscript to BioMed Central and take full advantage of:}

- Convenient online submission

- Thorough peer review

- No space constraints or color figure charges

- Immediate publication on acceptance

- Inclusion in PubMed, CAS, Scopus and Google Scholar

- Research which is freely available for redistribution

Submit your manuscript at www.biomedcentral.com/submit
C Biomed Central 